\title{
The Relevance of Genomic Epidemiology for Control of Tuberculosis in West Africa
}

\author{
Prince Asare*, Adwoa Asante-Poku, Stephen Osei-Wusu, Isaac Darko Otchere and \\ Dorothy Yeboah-Manu*
}

College of Health Sciences, Noguchi Memorial Institute for Medical Research, University of Ghana, Accra, Ghana

\section{OPEN ACCESS}

Edited by:

Martin Maiers,

National Marrow Donor Program,

United States

Reviewed by:

Joyce Wang,

University of Michigan, United States

Sanjay Gautam,

The University of Melbourne, Australia

Anou M. Somboro,

University of KwaZulu-Natal,

South Africa

*Correspondence:

Prince Asare

pasare@noguchi.ug.edu.gh

Dorothy Yeboah-Manu

dyeboah-manu@noguchi.ug.edu.gh

Specialty section:

This article was submitted to Infectious Diseases - Surveillance,

Prevention and Treatment,

a section of the journal

Frontiers in Public Health

Received: 07 May 2021

Accepted: 29 June 2021

Published: 23 July 2021

Citation:

Asare P, Asante-Poku A,

Osei-Wusu S, Otchere ID and

Yeboah-Manu D (2021) The

Relevance of Genomic Epidemiology

for Control of Tuberculosis in West

Africa. Front. Public Health 9:706651.

doi: 10.3389/fpubh.2021.706651
Tuberculosis (TB), an airborne infectious disease caused by Mycobacterium tuberculosis complex (MTBC), remains a global health problem. West Africa has a unique epidemiology of TB that is characterized by medium- to high-prevalence. Moreover, the geographical restriction of $M$. africanum to the sub-region makes West Africa have an extra burden to deal with a two-in-one pathogen. The region is also burdened with low case detection, late reporting, poor treatment adherence leading to development of drug resistance and relapse. Sporadic studies conducted within the subregion report higher burden of drug resistant TB (DRTB) than previously thought. The need for more sensitive and robust tools for routine surveillance as well as to understand the mechanisms of DRTB and transmission dynamics for the design of effective control tools, cannot be overemphasized. The advancement in molecular biology tools including traditional fingerprinting and next generation sequencing (NGS) technologies offer reliable tools for genomic epidemiology. Genomic epidemiology provides in-depth insight of the nature of pathogens, circulating strains and their spread as well as prompt detection of the emergence of new strains. It also offers the opportunity to monitor treatment and evaluate interventions. Furthermore, genomic epidemiology can be used to understand potential emergence and spread of drug resistant strains and resistance mechanisms allowing the design of simple but rapid tools. In this review, we will describe the local epidemiology of MTBC, highlight past and current investigations toward understanding their biology and spread as well as discuss the relevance of genomic epidemiology studies to TB control in West Africa.

Keywords: genomic epidemiology, tuberculosis, West Africa, Mycobacterium tuberculosis complex, Mycobacterium africanum, tuberculosis control

\section{INTRODUCTION AND BACKGROUND}

\section{Tuberculosis Historical Trends and Current Burden}

Tuberculosis (TB) is a disease of antiquity and eradication of it has been man's dream throughout history. Before the 19th century, very little was known about the causative pathogen and disease mechanisms. During the 17th to 19th centuries, reports indicated that 1 in every 5 adults had TB and mortality was 900 deaths per 100,000 population in the western world. TB accounted for $20 \%$ of all human deaths at the time (1). The history and perspective of TB was changed dramatically on March 24, 1882, with presentation by Robert Koch titled, Die Aetiologie der Tuberkulose, to the 
Berlin Physiological Society where Dr. Koch demonstrated the etiology of the disease and presented Mycobacterium tuberculosis as the causative agent (2).

The identification of the causative pathogen paved the way for several studies aimed at understanding the biology and the development of control tools including therapy. Antimycobacterial treatment began with the isolation of streptomycin (first isolated from Streptomyces griseus in 1944 by Albert Schatz, Elizabeth Bugie and Selman Waksman) followed in the 1950s and 60s by isoniazid and rifampicin (1). Nevertheless, TB persisted and does remain one of the leading causes of death among adults by a single infectious disease. TB affects millions of people annually so much so that in 1993 it became the first infectious disease to be declared a global health emergency by the World Health Organization (WHO). According to WHO estimates, about a quarter of the world's population are latently infected with the causative microorganism (3), thus, creating a pool of future active cases. Globally, in 2019 alone, an estimated 10 million new TB cases occurred, out of which 1.4 million died of TB making TB still the number one infectious disease killer by a single agent (4). Although the WHO African region is home to only $14 \%$ of the world's population, in 2019 it reported a quarter $(25 \%, 2,460,000)$ of the global TB incidence, and currently has the highest HIVassociated TB cases and case fatality rates (4). This makes subSaharan Africa the most burdened region based on case to population ratio. Three of the 17 West African countries (Nigeria, Liberia, and Sierra Leone) are among WHO's list of 30 high TB burden countries globally. In addition, Nigeria, Liberia, Ghana, and Guinea Bissau also add up to WHO's list of the 30 high TB/HIV burden countries in the world. In 2019, 9 out of the 17 West African countries had TB incidence rate of $>99$ per 100,000 population per year compared to global incidence of 130 per 100,000 population per year.

To reduce this high TB burden, the WHO put in a strategy known as the "End TB Strategy" in 2014 with set targets to reduce the absolute number of TB deaths and TB incidence by 90 and $80 \%$ respectively by 2030 and 95 and $90 \%$ respectively by 2035 (5). The End TB strategy was unanimously endorsed in May 2014 by all members of the WHO and the United Nations (UN) who proceeded to adopting the UN Sustainable Development Goal (SDGs) in September 2015. The End TB strategy outlines three pillars including; (1) an integrated, patient-centered care and prevention, (2) bold policies and supportive systems, and (3) intensified research and innovation (5). Generally, the control strategy calls for improving diagnostic, intervention, and research tools to facilitate achieving the set targets. Currently, the annual rate of global TB incidence decline is about $2 \%$, and this is far lower than the target of $10 \%$ set by the End-TB and SDG strategies. Also, per the End TB strategy, between 2015 and 2020, the total number of TB incidence rate and deaths were expected to have been reduced by 20 and 35\%, respectively; however, only 9 and $14 \%$, respectively were achieved.

\section{The Causative Agent of Tuberculosis}

Tuberculosis in mammals is mainly caused by 9 genetically related mycobacterial species comprising Mycobacterium tuberculosis sensu stricto (Mtb), M. africanum (Maf), M. bovis, M. mungi, M. microti, M. caprae, M. pinnipedii, M. suricattae, and $M$. orygis together referred to as the $M$. tuberculosis complex (MTBC) (6-9). The members of the MTBC are intracellular pathogens of mammals whose primary niche is the lungs $(6,10$ 15). Despite their close genetic relatedness, the MTBC differ in host specificity, although there are occasional cross-species infections (Figure 1). The main human pathogens are Mtb and Maf together referred to as human-adapted MTBC (hMTBC) $(6,12,13)$. The animal adapted MTBC (aMTBC) comprising $M$. bovis mainly infects cattle and sheep, $M$. caprae infects goats, $M$. microti infects rodents, $M$. pinnipedii infects sea seals and sea lions, M. mungi infects Mangoose, Dassie bacillus infects Dassies, M. suricattae infects meerkats, and Chimp bacillus infects Chimpanzees whereas $M$. orygis infects antelopes $(6-11,16)$.

Maf is endemic in only West-African countries and is responsible for about $50 \%$ of $\mathrm{TB}$ cases in some of the countries $(12,17-19)$. Thus, in addition to dealing with the general burden of TB, West Africa has an extra burden to deal with a two-inone pathogen.

\section{Control of Tuberculosis and Its Challenges}

The traditional methods for TB control depend on vaccination, early case detection of the affected using both clinical and laboratory-based tests followed by antimicrobial treatment of confirmed cases. TB vaccination has however, largely failed the fight against adult TB because the only WHO approved $M$. bovis-bacille Calmette-Guérin (BCG) vaccine administered to over $90 \%$ of newborns and in use since 1921 offers mainly protection against disseminated $\mathrm{TB}$ in children under 5 years as its efficacy wanes with time $(20,21)$. The current TB burden could be reduced considerably with a potent vaccine that is able to either induce clearance of latent infections or protect against new infection or both. Thus, early case detection followed by appropriate treatment remains the better option for TB control. Nevertheless, due to severe stigmatization, TB cases delay in reporting to the formal sector case management (22), which contributes to the high case fatality report by some of the countries including Ghana (23).

Laboratory methods used for diagnosis of TB include sputum smear microscopy, nucleic acid based assays, and culture. Smear microscopy prepared directly from sputum specimens is the most widely used test for diagnosing TB in West-Africa, though slowly being replaced by Gene Xpert. Molecular based tests are becoming the preferred test for diagnosing TB as most of them can simultaneously detected drug resistance. Two most widely used assays within the region are the Gene $\mathrm{Xpert}^{\circledR}$ MTB/RIF assay (Cepheid, USA) and the line probe assay (LPA) developed by Hain life sciences ( $\mathrm{GmbH}$, Nehren, Germany). The Gene Xpert which simultaneously detect TB as well as rifampicin (RIF) resistance directly from sputum has replaced direct sputum microscopy as the primary tool for diagnosing TB in countries like Ghana $(3,4,24)$. The LPA which offers a wider spectrum of test including the ability to test for resistance to RIF, isoniazid (INH) fluoroquinolones (FQs), and injectable aminoglycosides (AMG) (GenoType MTBDRsl) $(3,25)$ is more used in second/third level laboratories. 

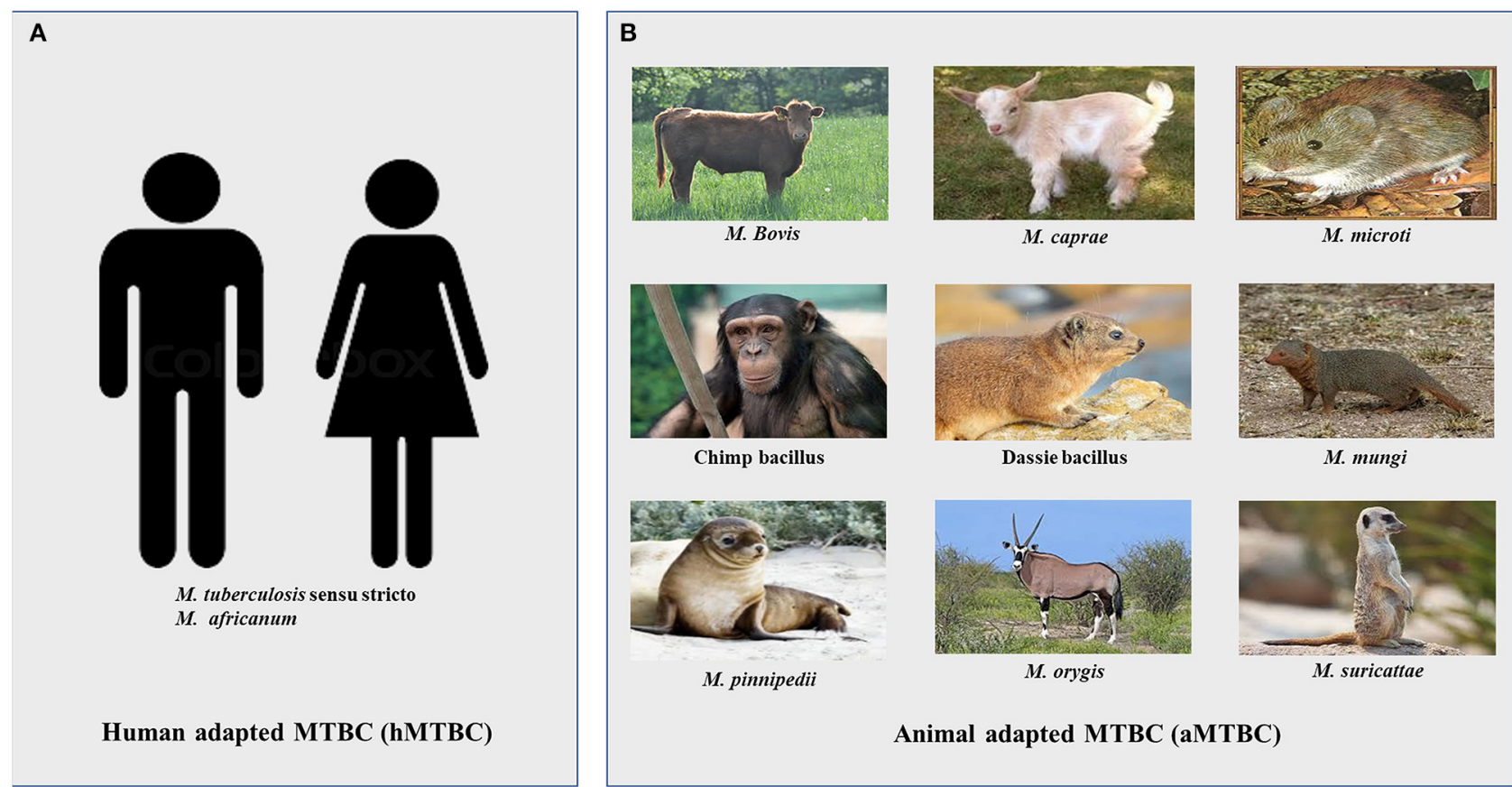

FIGURE 1 | Members of the Mycobacterium tuberculosis complex. (A) Human adapted Mycobacterium tuberculosis complex (hMTBC) (B) Animal adapted Mycobacterium tuberculosis complex (aMTBC).

The West-African regions follows the WHO approved case classification for anti-TB therapy. Drug sensitive active TB cases are treated with a 6-month multi-drug therapy which includes INH, RIF, pyrazinamide (PZA), and ethambutol (EMB) (26) which has $\sim 85 \%$ treatment success (4). However, there are recent reports of the emergence and high burden of drug resistant TB in the regions (27-30). Drug-resistant TB remains a public health threat. Treatment for drug resistant $\mathrm{TB}$ is quite cumbersome requiring at least 9 months (9-20 months) administration of relatively more toxic and expensive drugs such as FQs and AMGs sometimes in combination with linezolid, bedaquiline, and delamanid (4).

Challenges against TB control include socio-economic factors (such as weak health systems, increased urbanization and stigma leading to late reporting); pathogen related factors (such as emergence of drug resistant strains); lack of political will to commit funds and resources for control activities and the HIV epidemic. Lack of cheap but effective sensitive diagnostic tools and limited knowledge of the genome biology of the causative pathogen as well as the transmission dynamics of circulating strains are other equally important factors that hinder TB control. Nevertheless, traditional methods for evaluating TB control programs relies mainly on the number of cases detected and how many were cured, neglecting very crucial questions such as: the duration of infectivity, the frequency of reactivation, and the risk of progression among the infected contacts or the risk of transmission. Various molecular typing tools have been used in molecular epidemiological investigations for studying circulating MTBC strains to aid in TB control (31-33). However, whole genome sequencing (WGS), which has been made possible by the advent and increase in next generation sequencing (NGS) technologies offers the ability to study the genome of MTBC. WGS is crucial for genomic epidemiological investigations which is important for in-depth insight of the nature of pathogens, detecting circulating strains, monitoring resistance, evaluating interventions, and tracking the evolution of the pathogen hence providing a headway to achieve the End TB strategy (5). The SDG and End TB Strategy targets set for 2030 cannot be met without intensified research and innovation. In subsequent sections, we describe in detail some tools for probing MTBC genome, the local epidemiology of MTBC, highlight past and current investigations toward understanding their biology and spread as well as discuss the relevance of genomic studies to TB control in West Africa, the only sub-region that has to deal with a two-in-one pathogen.

\section{GENOTYPING TECHNIQUES FOR EPIDEMIOLOGICAL STUDY OF MYCOBACTERIUM TUBERCULOSIS COMPLEX}

Since the early 1990s, several genotyping tools have been proposed for the study of genetic diversity among the MTBC. These tools have been found to be discriminatory enough to distinguish unrelated strains as well as identify closely related strains. Genotyping of MTBC offers several advantages. In particular, it helps to distinguish between new infections and reactivated cases as well as identify predominant genotypes. 
The classical genotyping methods that have been used to understand genetic diversity among MTBC include large sequence polymorphism (LSP) typing (34), single nucleotide polymorphism (SNP) typing (35), spacer oligonucleotide typing (spoligotyping) (36), insertion sequence 6110 (IS6110) restriction fragment length polymorphism (IS6110 RFLP) typing (37) and mycobacteria interspersed repetitive unit-variable number of tandem repeats typing (MIRU-VNTR) (38) and currently, WGS $(39,40)$.

\section{Large Sequence and Single Nucleotide Polymorphism Typing}

Large sequence polymorphisms (LSPs) and single nucleotide polymorphisms (SNPs) are phylogenetically robust and stable molecular markers for strain identification. They are unique irreversible events and less prone to distortion by selective pressure due to lack of horizontal gene exchange in MTBC and this makes them less prone to convergent evolution $(12,41)$. Most importantly, LSPs also known as regions of differences (RDs) (34) have been used to define several discrete strain lineages within the hMTBC specific for different human populations and geographical regions and unravel the evolutionary scenario of ecotypes of MTBC $(6,42)$. SNPs have also been used to study the biology of the MTBC as a pathogen with very restricted genetic diversity (35). However, these typing tools do not allow the calculation of genetic distances and also cannot completely resolve all deep-rooting branches of the MTBC phylogeny (43).

\section{Spoligotyping}

This tool was developed in 1997 by Kamerbeek et al. (36) and is based on polymorphisms in the clustered regularly interspaced short palindromic repeats (CRISPRs) region of MTBC. Spoligotyping is the most frequently used PCR-based approach for studying the phylogeny of MTBC in high incidence areas. Spoligotyping is simple, cost-effective, and high-throughput with accurate and reproducible results within 2 days. However, it is less discriminatory; it targets only a single genetic locus, covering $<0.1 \%$ of the MTBC genome. Its direct application on clinical samples without the need for prior culture and easy interpretation and computerized binary (present/absent) data format makes it suitable for molecular epidemiological studies. Direct (from sputum samples) and indirect (using cultured isolates) spoligotyping are both efficient in studying the phylogeny of MTBC, however, in regions with high prevalence of polyclonal infection such as sub-Saharan Africa where all MTBC lineages are present, it is recommended to rule out mixed infection by combining MIRU-VNTR and spoligotyping for more accurate results (44).

\section{IS6110-RFLP}

The first genotyping method developed in the early 1990s by van Embden et al., to be used for strain classification was RFLP based on IS6110 insertion sequence (IS6110-RFLP) (37). Initially, considered as the gold standard for transmission studies, this method has been replaced by other methods for various reasons: it is labor intensive, requires high quality DNA, sophisticated and expensive computer software to analyse, experienced personnel of high technical expertise to interpret the results and most importantly, it is not discriminatory enough for strains with 6 or less IS6110 copy numbers like some strains of M. bovis. Nonetheless, it paved the way for an in-depth understanding of the diversity among MTBC before the development of the more recent methods.

\section{MIRU-VNTR Typing}

This is one of the most widely used typing tool and is based on tandem repeat elements dispersed in intergenic regions of the MTBC genomes and copy number diversity (38). Currently, it has become the most reliable and efficient conventional genotyping system for TB transmission studies and has replaced IS6110RFLP. This method has been widely adopted and successfully used in a variety of TB molecular epidemiological studies to trace on-going chains of TB transmission, differentiate relapse from re-infection cases and detect laboratory cross-contamination (43, 45) due to its reproducibility, portability, high discriminatory power, and standardization $(33,43,45-49)$. However, it is laborintensive due to a high number of individual PCRs required and less informative in areas with restricted MTBC lineages $(43,50-52)$.

\section{Whole Genome Sequencing as a Typing Method}

WGS is increasingly becoming the preferred technique for TB research. WGS determines the complete DNA sequence of an organism's genome at a single time and can provide several answers at a single time, making it the ideal tool for studying the pathogen. With WGS springing up, molecular epidemiology has gradually evolved to become genomic epidemiology. Several studies have applied large-scale WGS to different aspects of TB research; to accurately infer phylogeny $(39,40)$, to study the biology of the MTBC, and also to study chains of transmission $(53,54)$ and disease outbreaks $(55)$. Furthermore, WGS has been used to identify drug-resistance associated mutations including; finding mutations compensating for the fitness defect associated with rifampicin resistance (56-58) and rapidly identify drug resistance mutations of an XDR-TB patient (59). These studies demonstrate the potential for future routine applications of WGS in research and genomic epidemiology. However, the use of WGS for large-scale applications especially in endemic areas is limited by its cost and the needed specialized expertise for analyses. A drawback of the current use of WGS in most TB research is that sequencing is mostly carried out on cultured isolates and analyzed using the dominant alleles present without considering within-host diversity. This can however be circumvented by investing in culture-free metagenomics-based approaches.

\section{PHYLOGEOGRAPHY OF THE MTB AND MAF}

Similar to other monomorphic bacterial pathogens such as $M$. leprae and Bacillus anthracis, MTBC exhibits low DNA sequence diversity and lack of horizontal gene transfer compared to other bacteria (35). 


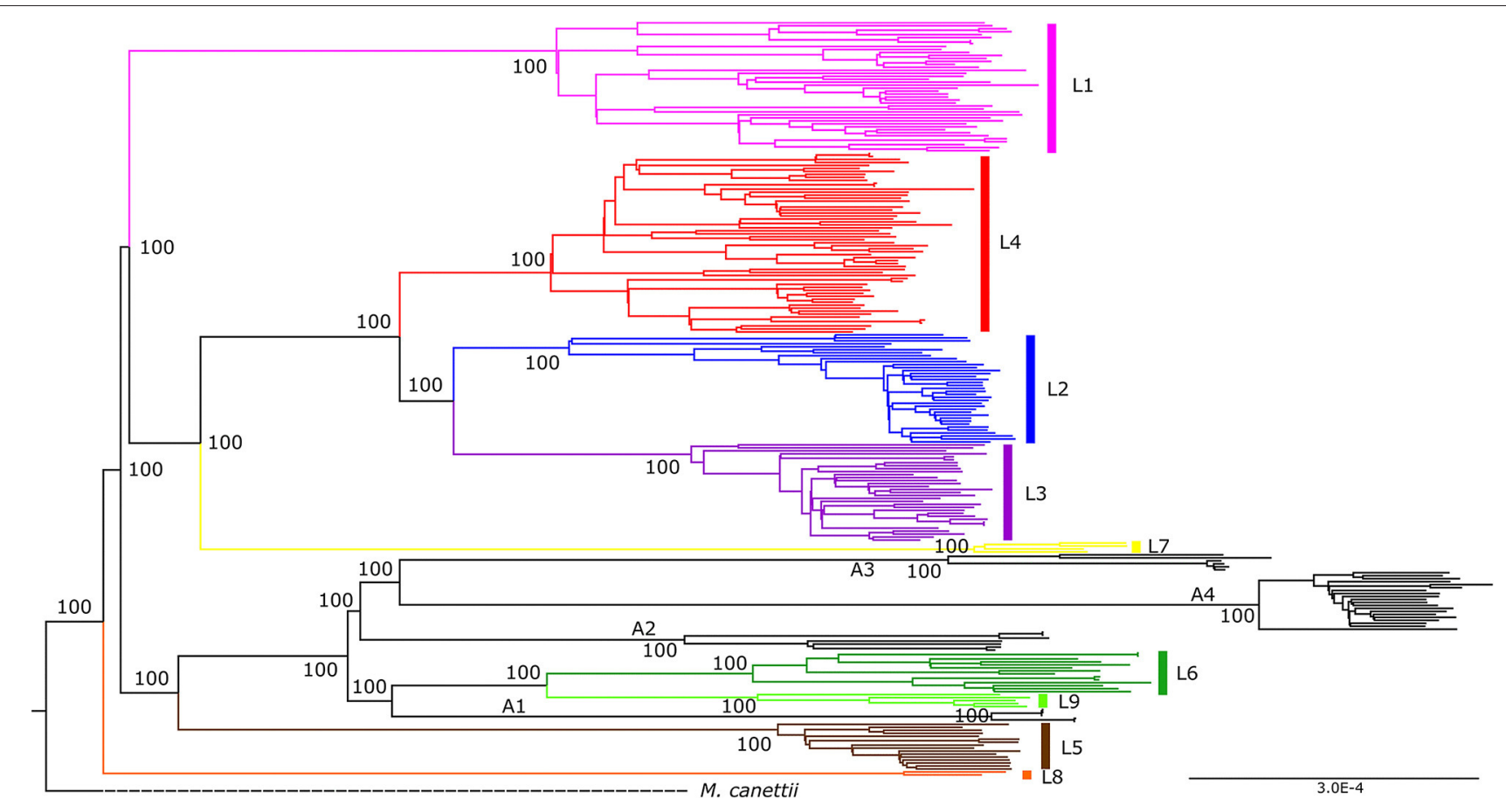

FIGURE 2 | Maximum-likelihood phylogeny of the Mycobacterium tuberculosis complex using whole genome sequencing. The phylogeny is rooted on M. canettii and bootstrap values shown for nodes. The traditional hMTBC color coding of the first 7 lineages (L1-L7) were used whereas animal adapted members are given the color black. The newly described lineages, L8 and L9 are colored orange and light green respectively [adapted from Coscolla et al. (40)].

The hMTBC were split into 7 main phylogenetic lineages (L) using specific LSPs and SNP markers (42, 60). Lineage 1, L2, L3, L4, and L7 are classified under Mtb whereas L5 and L6 are under Maf. Two additional lineages namely L8 (61) and L9 (40) have been recently identified resulting in 9 phylogenetic lineages of the hMTBC (Figure 2). Nevertheless, L1 to L6 are the main phylogenetic lineages based on the number and proportion of characterized isolates. Using the currently available highly discriminatory genotyping tools, several sub-lineages, and genotypes have been identified among these main phylogenetic lineages of the hMTBC $(40,62-66)$.

Analyzing the diversity of the hMTBC in conjunction with the country of isolation led to the discovery of different distribution patterns of the various lineages across the globe (12). Whereas, Mtb lineages with the exception of L7 (found at the Horn of Africa) are globally ubiquitous (prominent among them being L4), those of Maf (L5 and L6) are found in West Africa (67). Thus, in addition to dealing with the general burden of TB, West Africa has an extra burden to deal with a two-in-one pathogen. Although Maf is unique to West Africa, its prevalence varies by country. Using molecular genotyping results, the prevalence of L5 increases from West to East and appears highest in Benin (39\%) and Ghana (21\%), while that of L6 increases from East to West, highest in Guinea Bissau with 51\% of smear-positive TB caused by L6 (67).

The observed associations between hMTBC lineage and country of origin under cosmopolitan clinical setting as well as between pathogen lineage and ethnicity within country point to a potential host-pathogen coevolution of the hMTBC and humans $(42,68,69)$. Based on this geographical distribution pattern of hMTBC lineages, two groups namely specialists (limited to specified geographical locations) and generalists (found everywhere) have been proposed (70). L4 is generally described as a generalist lineage whereas L5 and L6 are specialists. Nevertheless, some distinct L4 sub-lineages, are restricted to specified geographical settings including the Uganda, Cameroun and Ghana genotypes (70). It is also possible that the disparate geographical spreading of hMTBC genotypes maybe explained by historical eventualities such as emerging of specific genotypes in regions that later championed colonization and globalization $(39,70,71)$. Nevertheless, the potential contribution of biological traits that promote coevolution of specific hMTBC genotypes and certain human populations cannot be understated as evidenced by the San Francisco study which found associations between hMTBC lineage and country of origin of the affected TB patients (42).

\section{GENOME BIOLOGY OF THE MTBC AND ITS SIGNIFICANCE TOWARD THE CONTROL OF TB IN WEST AFRICA}

The annotated $\mathrm{H} 37 \mathrm{Rv}$ genome revealed a genome size of $4.4 \mathrm{Mbp}$ containing $\sim 4,000$ genes. The annotated genes include those encoding proteins involved in intermediate metabolism and respiration $(877 ; 22.0 \%)$, lipid metabolism 
(225; 5.7\%), information pathways (207; 5.2\%), virulence, detoxification and adaptation $(91 ; 2.3 \%)$, cell wall and cell processes $(517 ; 13.0 \%)$, regulation $(188 ; 4.7 \%)$, supposedly conserved hypothetical functions $(911 ; 22.9 \%)$ and unknown functions $(607 ; 15.3 \%)$. Non-protein-coding regions including, genes encoding stable RNAs $(50 ; 1.3 \%)$, insertion elements and remnants of bacteriophages $(137 ; 3.4 \%)$ and those rich with PE (Pro-Glu) and PPE (Pro-Pro-Glu) were also identified. The MTBC has extremely high number of genes involved with fatty acid metabolism, especially those associated with $\beta$-oxidation of fatty acids which are over $100(2.5 \%)$ compared to $50(1.2 \%)$ genes found to perform the same function in E. coli $\mathrm{K}-12$ $(72,73)$. This large number of the MTBC enzymes dedicated to fatty acid catabolism enhances its ability to thrive in tissues of the infected host, where fatty acids are the major source of carbon (72). Additionally, the presence of glycine rich proteins of the PE (74) and PPE (71) families is unique to the members of the MTBC. Actual functions of these PE/PPE genes are not clearly deciphered. However, similar genes in M. marinum have been associated with virulence. Furthermore, antigenicity of some localized PE subfamily of proteins called PGRS (polymorphic GC-rich repetitive sequence) with conserved PE domain followed by Gly-Gly-Ala or Gly-Gly-Asn have been found which underscores the potential implication of these genes in the ability of the MTBC to cause disease.

Comparative genomics analysis of MTBC strains shows little to no evidence of horizontal gene transfer in either hMTBC or aMTBC strains $(43,75-78)$. This has been attributed to the evolved intracellular adaptation leading to the typical clonal nature of members of this complex compared to most nonmycobacteria and some atypical mycobacteria including $M$. abscesses and M. avium (39, 43, 79). Genome diversity within the MTBC thence arise mainly from SNPs comprising insertions, deletions, and substitutions and LSPs including duplication and/or transposition of mobile genetic elements as well as deletion of genetic elements accounting for the different host adaptations, disease phenotypes, and response to interventions $(76,80)$.

Despite lack of evidence of horizontal gene transfer within the MTBC, recent comparative genomics of the MTBC showed substantial strain diversity among the different members which could have functional implications especially in West Africa where the highest diversity of the MTBC is found (40,81-87). Comparing the first Maf whole genome sequence (L6 strain GM041182) to $\mathrm{H} 37 \mathrm{Rv}$ revealed the presence of a unique sequence RD900 encoding a protein involved with trans-membrane transportation of macromolecules. This sequence is also present in all so-called "ancient" lineages of the MTBC including L1, L5, L6, and L7 but independently lost in all "modern" lineages including L2, L3, L4, and M. bovis. Conversely, the Maf genome shares a number of uniquely lost genes with $M$. bovis but not Mtb including genes for biosynthesis of some vitamins arising from pseudogenization. In addition, the L6 genome has an intact copy of the gene (iniA) capable of increasing its susceptibility to antibiotics that are not active against $\mathrm{Mtb}(88,89)$. It has also been shown that, all classical hMTBC strains have a conserved $m p t 40$ gene which is missing from the genomes of all classical aMTBC an indication of specific host adaptation (90) a discovery that has been incorporated into a rapid nested assay for differential diagnosis of TB (91).

The effects of genomic diversity among bacterial pathogens such as Escherichia coli, Neisseria menigitidis, Haemophylus influenzae, Bordetella, and Streptococcus species are welldocumented (92-97). In these species, some strains are more likely to cause invasive disease than others though expression of distinct virulent toxins (93). No such genetic marker (s) has been identified for the MTBC albeit infection by different genotypes results in a range of clinical phenotypes ranging from asymptomatic infection through localized diseased lungs to different forms of disseminated disease $(98,99)$. However, it is likely that specific MTBC genotypes have distinct genetic traits which influence the immune response elicited by the host, and subsequently the outcome of the host-pathogen interaction (100, 101). This assertion is supported by findings from in vivo and ex vivo model studies involving different MTBC lineages, indicating that $\mathrm{Mtb}$ lineages such as the L2 are more virulent compared to the West-African specific lineages, L5 and L6 (11, 45, 102, 103).

Clinical studies comparing Mtb and Maf (mostly L6), found statistical association between Mtb infection and early progression to active pulmonary $\mathrm{TB}$ disease relative to Maf, suggesting that $\mathrm{Mtb}$ is more virulent compared to Maf $(67,98,104-106)$. Numerous genotype-specific mutations in genes of functional categories such as intermediate metabolism and respiration, cell wall and cell processes, lipid metabolism, regulatory proteins, information pathways and virulence, detoxification, and adaptation could be responsible for the differential presentation of infection by different lineages. Comparative target gene sequence analysis of MTBC lineages found that approximately two-thirds of all SNPs in coding genes are non-synonymous SNPs (nsSNPs) thus underscoring the potential implications of the limited genomic diversity within the MTBC compared to other bacteria $(13,74,79,107)$. Other than SNPs, the reductive evolution of the MTBC involving the genomic deletion of blocks of specific genomic regions including phylogenetic markers can involve blocks of diverse functional genes including but not limited to those associated with immunogenicity and/or host evasion (12, 108, 109). This observation is attributed to the deletion of RD1 a genetic evolutionary event similar to what transpired leading to the generation of the only WHO approved TB vaccine $M$. bovis BCG vaccine from continuous in vitro passage of $M$. bovis. The RD1 encodes the es $x 1$ locus which is responsible for the type VII secretory system driving the secretion of germane $\mathrm{T}$ cell antigens ESAT- 6 and CFP-10 associated with pathogenicity of the MTBC (110-112).

Recent comparative genomics analysis of MTBC including large number of Maf genomes have revealed many insightful lineage-specific genomic events. For instance, different pairwise SNP distances within lineages $(76,84)$, different average pairwise nucleotide diversity of annotated genes (84), lineage-specific, and within-lineage accumulation of amino acid mutations (84, 85, $87,105)$ some of which could potentially affect the applicability of some control tools $(83,85)$. Additionally, in sillico pangenome analysis of hMTBC from West Africa identified impaired 
expression of mpt64 and mlaD genes specifically among L6. Whereas, the mpt64 encodes the immunogenic protein which is the basis of the mpt64 rapid TB diagnostics currently in use, the mlaD encodes a mammalian cell entry protein. Albeit there was no evidence of impaired expression of mpt64 among L5, an amino acid mutation I43N within the gene was found specifically among L5. These findings may potentially explain the low sensitivity of mpt64 -based diagnostics in West Africa where L5 an L6 cause up to $50 \%$ of TB $(83,85,113)$ as well as the reported slow progression of Maf infection to disease relative to that of $\mathrm{Mtb}$ (98). Also, a couple of Maf specific amino acid mutations were found within the esx-1 secretory system which drives secretion of T cell antigens ESAT- 6 and CFP-10 associated with virulence in the MTBC (114). Interestingly, the ESAT- 6 and CFP-10 are the backbone of the many interferon gamma release assays used for diagnosis of TB (115) and some potential TB vaccines in different phases of development (116, 117) which could potentially affect the applicability of these interventions in West Africa. Furthermore, essential genes of the MTBC irrespective of lineage were found to be highly conserved and under purifying selection. However, when comparing $\mathrm{T}$ cell epitopes, genotypes that are widely distributed such as L4 sub-lineage LAM were significantly diverse compared to T cell epitopes of specialist genotypes such as L5 and L4 Uganda genotypes $(40,70,84)$. Unexpectedly, T cell epitopes of L6 which is described as a specialist pathogen due to its restriction to West Africa were under positive selection contrary to those of L5 which is also restricted to West Africa. This observation coupled with the statistical association of L5 with ethnicity in West Africa and association of L6 with HIV/AIDS suggest that L5 and L6 may be restricted to West Africa by different biological processes $(18,68)$. Thus, L6 could potentially be an opportunistic pathogen with an unknown environmental reservoir specific to West Africa (84).

In spite of these indications, exactly how MTBC genomic diversity influences disease progression and presentation as well as the distribution of various lineages and their potential impact on control of TB remain poorly understood. This calls for additional research that seeks to comparatively assess the clinical and ecological implications of MTBC genomic diversity using strain collection that encompass MTBC isolates from every part of the globe toward efficient control of TB.

\section{MTBC SURVEILLANCE AND TRANSMISSION IN WEST AFRICA}

Surveillance activities geared toward understanding MTBC transmission are necessary to complement conventional control efforts to allow the establishment of good preventive strategies, appropriate therapy, and a better understanding of the pathogen biology thereby contributing to the development of future control tools and ultimately helping eliminate TB. These surveillance activities are specifically needed (1) To correctly identify, characterize and track MTBC lineages/strains; (2) To detect risk factors associated with the disease; (3) To understand MTBC person-to-person transmission dynamics, which has been studied extensively in developed countries of North America and
Europe as well as other parts of the world and has been useful for identification of outbreaks as well as most at risk groups (33, 48, 118-120) for targeted control activities and; (4) To track TB strains among recurring $\mathrm{TB}$ patients and provide indications of the cause of secondary case source (121-123), for appropriate treatment, evaluation of performance and epidemiology (32, 124). To effectively control TB in West Africa, it is therefore paramount to undertake such investigations in a populationbased scale which will contribute to knowledge on factors that enhance spread of the disease in the sub-region.

The molecular typing tools discussed earlier have not only been used to study MTBC biology but also for surveillance purposes through molecular epidemiological investigations. Although the typing tools possess varying discriminatory power $(32,125-129)$, they have been used widely in advanced countries to help monitor MTBC spread especially among prisoners and cross country travelers (130-133). In West Africa, findings from surveillance studies have revealed in-depth knowledge of the varying distribution of Mtb and $\operatorname{Maf}(134,135)$ and has called for further studies to investigate their transmission dynamics within respective geographical areas. This has a great public health value considering that members of the MTBC do not all have the same disease phenotype hence the need to survey to obtain knowledge of circulating genotypes. Some interesting observations has been made over the years from surveillance activities conducted in West Africa. For instance, as identified elsewhere (136-141), an association between Beijing strains of L2 and drug resistance has been reported in Benin including the identification of a possible streptomycin-resistant Beijing outbreak $(142,143)$ and similarly, through surveillance activities conducted in Ghana, the Ghana genotype of L4 has been linked to drug resistance $(19,144)$. The spread of difficult-to-treat drug resistant strains are also monitored through surveillance activities $(31,132,145,146)$. Until recently, drug resistant clones were thought to be less fit and less likely to transmit from person to person; however recent surveillance studies in Ghana, Nigeria, and other parts of the world have documented evidence of transmission of both INH resistant strains and MDR even though not involving large clusters $(53,118,147,148)$. There is therefore the need to identify and control such difficult-to-treat drug resistant clones to stop their spread through surveillance activities. WHO currently supports the inclusion of NGS to provide detailed information on drug resistance across multiple gene regions directly from sputum specimens, however the WHO is yet to review and approve current protocols (4). Also, through surveillance activities, zoonotic TB spillover has been observed in West Africa with indications that individuals who are in direct constant contact with livestock and/or dairy products are at major risk of contracting zoonotic TB (19, 149, 150). Finally, among others, surveillance activities in the sub-region has led to the observation that the West African restricted Maf specie has reduced transmissibility (45), has decreased sensitivity to some available diagnostics (83), has poor progression to active disease $(98,151)$, has poor treatment outcome $(152,153)$ and has been found to be associated with some endemic ethnic groups $(18,68)$.

With the advent of new genotyping techniques, surveillance activities are made more meaningful through MTBC 
transmission studies. The MIRU-VNTR typing tool has over the years been widely adopted and together with epidemiological data used in a variety of TB transmission studies for the detection of recent TB transmission and outbreaks due to its portability, standardization, reproducibility, and high discriminatory power (31, 33, 45-49, 154, 155). However, only few West African studies have employed this tool for transmission studies to identify genetic and geographic TB clusters $(45,105,135)$. The discriminatory power of this largely adopted MIRU-VNTR typing tool may not be sufficient to distinguish unrelated strains for some geographical settings (126) especially in West Africa with the most diverse MTBC lineages, hence for TB transmission studies it is recommended that WGS, which is by far the ultimate tool for strain differentiation, be used to make decisive conclusions. Data generated from WGS offers the ability to accurately identify recent $\mathrm{TB}$ transmission and also to trace the direction of transmission between epidemiologically linked cases (156). However, this tool has not been readily utilized for MTBC transmission studies in West Africa probably because of the huge cost and expertise needed to analyze the generated data. This may not be a problem in the near future as WGS is gradually becoming less expensive. The recent increase in NGS technologies coupled with the competition among available sequencing platforms and the availability of simpler data analysis tools have made WGS an attractive molecular tool used in many surveillance and transmission investigations. Globally, the first report of an effective use of WGS for MTBC transmission investigation was in 2011 from Vancouver which involved the delineation of two unrelated transmission events among a cohort of drug users having identical MIRU-VNTR profiles following which it has been used in a large array of studies (148, 157-161). WGS has been useful in detecting unsuspected outbreaks hence it should be used not only as a research tool but as a surveillance tool to aid in providing the necessary guided steps to track, monitor, and control MTBC strains.

There exist varying reports on the transmissibility of members of the MTBC $(45,98)$. However, limited surveillance activities have suggested that Mtb transmits better than $\operatorname{Maf}(45,162)$. This is probably because Maf is thought to be attenuated compared to Mtb $(67,113,163)$. Although it is argued that Mtb is fitter than Maf, and with time it will outcompete the Maf population, this may not be true as two studies from the Gambia and Ghana have proven otherwise by observing a constant prevalence of Maf over a period of 7 and 8 years, respectively $(19,152)$. However, decline in Maf prevalence have been reported in a number of studies from Guinea-Bissau, Côte d'Ivoire, and Cameroon (164168). Some of these studies employed biochemical means for classification and perhaps might have misclassified the strains. There is therefore the need to invest more resources in using higher resolution tools such as the WGS for MTBC surveillance and hence transmission. Understanding MTBC transmission will contribute to knowledge on factors that enhance the spread of the disease, which is useful for developing preventive interventions and may have implications for the development and deployment of new TB vaccines and diagnostics. For instance, hotspots of TB transmission identified through a recent study in Ghana (53) offered the TB control program to direct some of their limited resources to targeted population groups for increased awareness and enhance screening activities. Also, using WGS, there is reported evidence of person-to-person transmission of Maf lineage 6 strains from Mali (87) confirming the propensity of the Maf species to also transmit (45).

Finally, through molecular surveillance activities, TB relapse are now correctly defined. Formally, all individuals who get a secondary episode of TB are referred to as having relapse. By definition, a disease is said to have relapse if the old infection bounces back. This is however not true for all secondary episodes of TB knowing that some individuals do come back with totally different strains compared to the previously infecting strain; such cases are technically referred to as exogenous re-infections rather than relapse. A secondary TB episode can be referred to as relapse only if the previous infecting strain is the same as the current one. Thankfully, current MTBC genotyping tools make it possible in most instances to distinguish between relapse and re-infection. This is possible because of the assumption that if strains from both episodes are genotypically/gnomically indistinguishable, it suggests relapse whereas distinguishable strains suggest reinfection. Predominance of relapse over re-infection indicates high-quality public health practices and a low risk of local transmission. Many studies have employed genotyping tools like MIRU-VNTR, IS6110 RFLP, and WGS technique to explore relapse and re-infection among TB patients (121-123, 169174). However, very few of these studies originated from West Africa. Majority of the few previous studies conducted in Africa have only employed large DNA-sequence based typing assays (ie. MIRU-VNTR and IS6110 RFLP) which can potentially be confounded by convergence evolution. This means that established relapse cases may not actually be relapse events hence we advocate for the use of WGS which is more robust and relatively free from convergence evolution. Using WGS, it was possible to accurately detect relapse from a Ghanaian cohort; this study identified a couple of individuals who were previously infected with drug sensitive strains but later had TB recurrence harboring drug resistant strains (121). This shows the possibility to track such recurring cases and highlights the need to foster genomic epidemiology to aid early detection of drug resistance emergence to provide an effective TB control. Such surveillance activities carried out using WGS data are currently not absolute and has a few limitations as the common practice has been to make judgements based on sequencing one isolate per individual at each time point neglecting the possibility of within-host bacteria diversity. However, it is possible to detect mixed infections (175). It is worth noting that the confidence in differentiating relapse and re-infection can be reduced without considering the various bacterial populations that may exist at a given time point. We acknowledge that such within-host diversities do exist, and current and future studies should consider it in their investigations.

\section{MECHANISM OF DRUG RESISTANCE EMERGENCE AND EVOLUTION}

The control of tuberculosis has been hampered by the emergence of drug resistance globally which threatens to make TB 


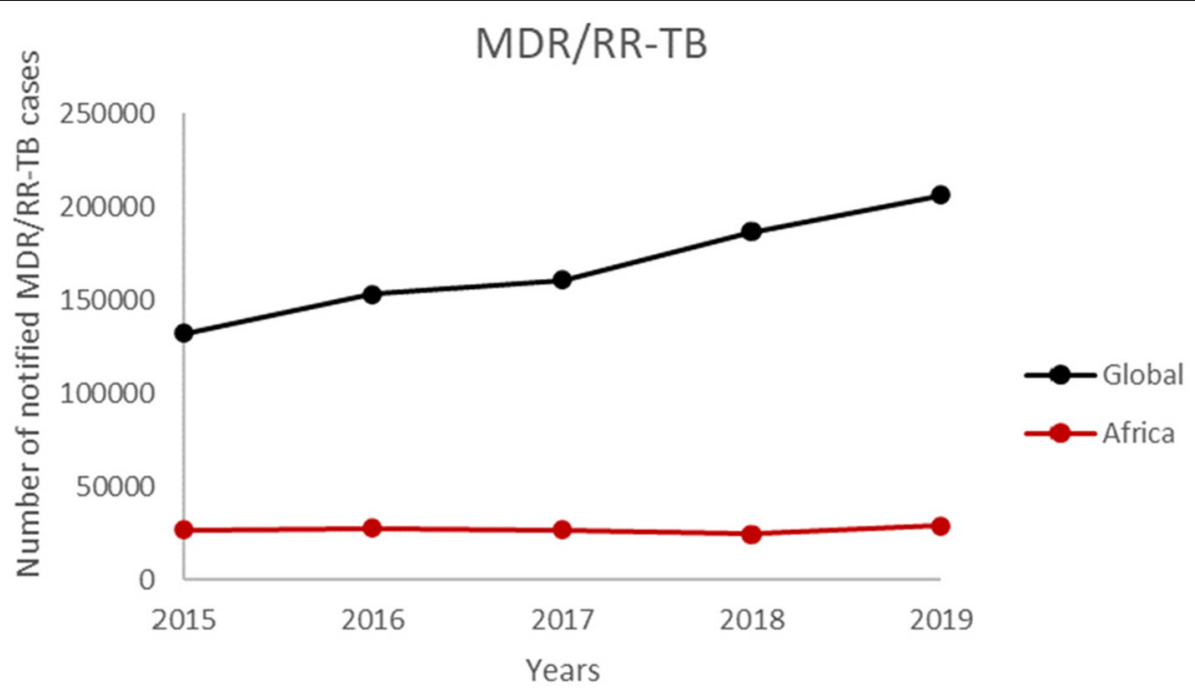

FIGURE 3 | The number of notified MDR/RR-TB cases by WHO member states from 2015 to 2019.

untreatable $(4,176)$. Drug resistant TB in the Africa region has been a major threat to the achievement of the goals of WHO's End TB Strategy and the SDGs in the region (4). The spread of these resistant strains mimics the pre-antibiotic era. According to the 2020 Global TB Report, about 0.5 million individuals developed rifampicin-resistant TB (RR-TB) and $78 \%$ of this number were confirmed as multi-drug resistant TB (MDR-TB) cases (4). The drug resistance $\mathrm{TB}$ cases contributed $3.3 \%$ of all new $\mathrm{TB}$ cases and $17.7 \%$ of previously treated people (4).

The threat posed by drug resistant TB strains can be mitigated by gaining a better understanding of the mechanism of the emergence of these strains and their evolution. With the recent advances in bacterial genomics using NGS, the molecular mechanisms of emergence, fixation, and transmission of drug resistant TB are being unraveled (177). However, there is the need to further assess the complexity of the emergence of drug resistant strains that have become a major challenge to the control of the disease. Comparative genomic studies have also shown that strain diversity could also be a major factor heightening the threat of TB drug resistance $(40,178,179)$. This section seeks to throw more light on the advances made toward deciphering the mechanisms of drug resistance especially among the West African genotypes of MTBC and to provide new directions for future studies.

There is paucity of data on TB drug resistance in subSaharan Africa which has always called for active surveillance to determine the true burden of DR in West Africa and Africa as a whole (178). The WHO initially reported the burden of drug resistance in West Africa based mainly on projected estimates. An active surveillance conducted by the West African Network of Excellence for Tuberculosis, AIDS and Malaria (WANETAM), on isolates from 2009 to 2013 showed an unexpectedly higher MDR-TB of $6 \%$ for new TB cases as compared to the $3.5 \% \mathrm{WHO}$ estimate in 2013 (180). Although the WHO estimated 20.5\% MDR-TB for retreatment cases (classified as patients who have been previously treated for TB and have reported again with the disease), the network reported 35\% for the eight West African countries $(28,180)$. In another study that screened isolates from the eight West African countries from 2012 to 2014, the authors also reported the same $6 \%$ MDR-TB for new cases and $34 \%$ for retreatment cases (30). This shows the prevalence of drug resistance in West Africa has been fairly constant and multidrug resistance has become an emerging health challenge in West Africa. The same trend is seen in the WHO Africa region where the number of notified MDR/RR-TB cases have been constant over a 5-year period (Figure 3).

Several studies have linked specific lineages/sub-lineages with drug resistance $(179,181)$. A typical example is the Beijing sub-lineage of MTBC which is associated with MDR-TB in Asia $(182,183)$. The propensity for some of MTBC genotypes to harbor resistance toward anti-TB drugs have been reported in the sub-region. For instance, the Ghana sub-lineage of L4 which is mainly restricted to West Africa has been found to be associated with drug resistance in Ghana (144). Comparative genomics analysis of hMTBC from Ghana revealed that INH resistant Mtb and Maf were significantly associated with katG and inhApro mutations, respectively (144). In a separate study, a univariate analysis revealed that L6 was less likely to be associated with INH resistance (18). In support of this, a most recent comparative genomics analysis of Maf has shown that L5 has a high genetic inclination toward development of drug resistance compared to L6 (40). West Africa is unique in its MTBC genotypes and evolution of drug resistance which calls for further molecular investigation. Although a number of the resistant isolates reported in the sub-region were sequenced and analyzed for the presence of mutations associated with drug resistance, there is still a lot that were only characterized by phenotypic methods $(18,28,30,144)$.

The number of WHO States with at least one reported case of XDR-TB has been increasing over the years (Figure 4). 


\section{WHO States with at least one case of XDR-TB}

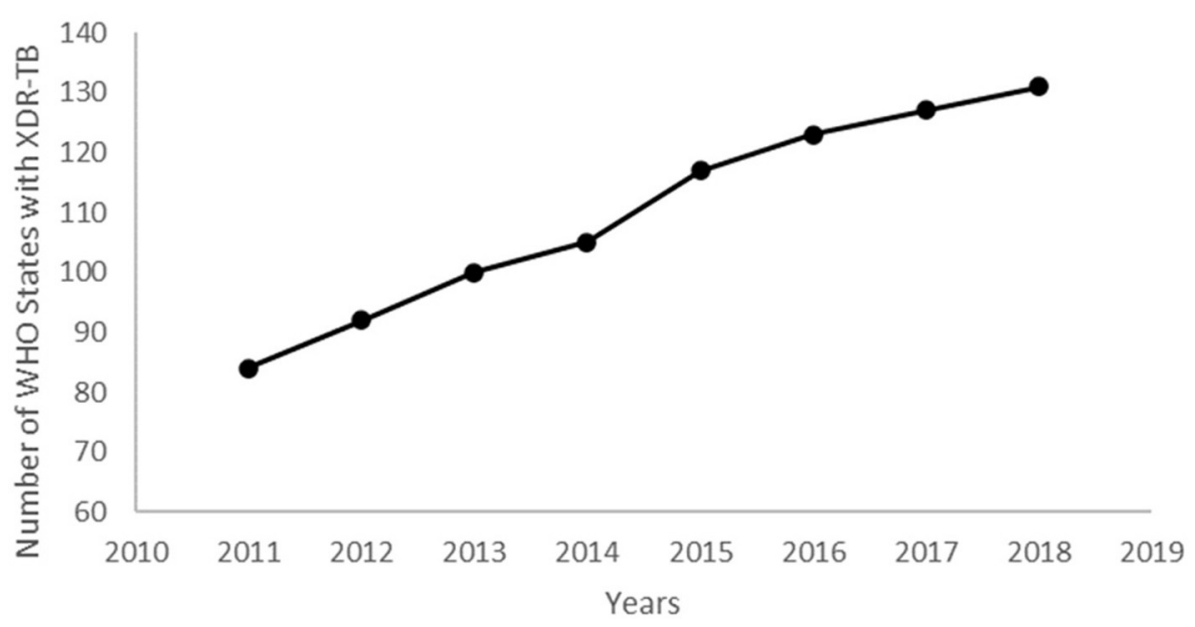

FIGURE 4 | The number of WHO member States with at least one confirmed case of XDR-TB.

\section{XDR-TB}

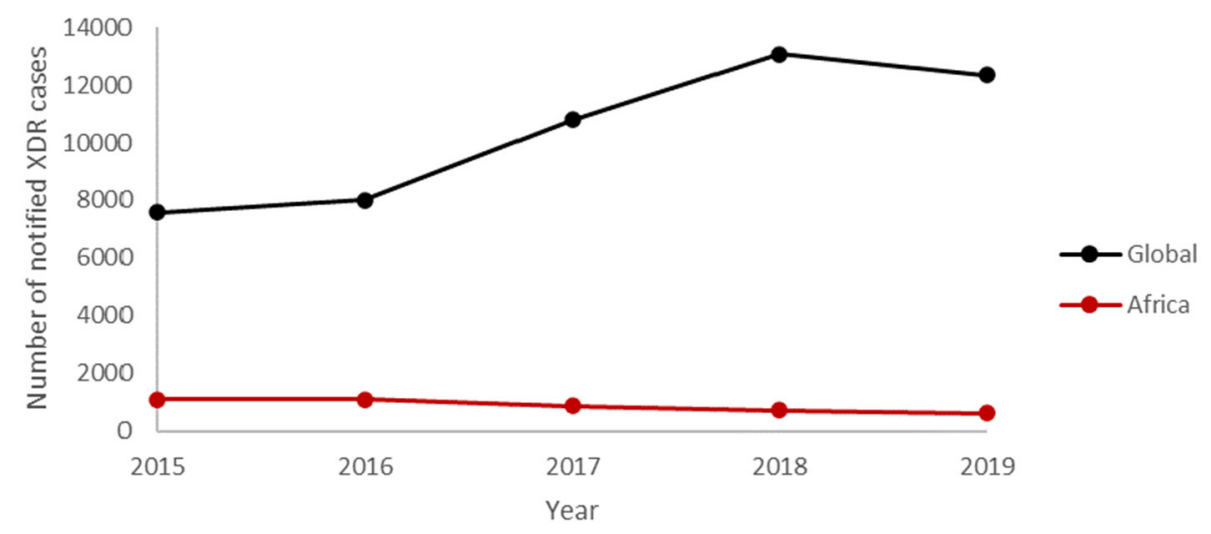

FIGURE 5 | The number of notified XDR-TB case from 2015 to 2019.

This confirms the spread of XDR-TB globally. The number of reported XDR-TB cases has been on the rise with that of Africa on a slight decrease (Figure 5). The DR picture for Africa might look different for different parts of the region.

The WANETAM reported the circulation of pre-XDR$\mathrm{TB}$, which is MDR-TB with additional resistance to either a fluoroquinolone or an aminoglycoside, among retreatment cases in all the eight countries in 2016 without any record of XDRTB. Interestingly, only Ghana and Togo had reported pre-XDR $\mathrm{TB}$ among new cases. It was not surprising when Ghana reported its first XDR-TB case in 2018 (29). Togo, together with BurkinaFaso and Niger had already reported at least one XDR-TB case in 2011 (184). This calls for more genomic studies in WestAfrica to understand the evolution and spread of DR-TB in WestAfrica.

\section{FUTURE PERSPECTIVE}

Despite these evidence of genomic diversity among the MTBC supported by phenotypic data including variable outcome of TB infections, differences in macroscopic morphology, niacin production, and inhibition by pyrazinamide $(185,186)$, most research supporting global interventions are largely based on limited and biased collection of isolates. The presence of a unique TB causing bacteria restricted to West-Africa makes it imperative for more genomic studies in the sub-region to improve the understanding of the biology of Maf and the functional implications of genomic diversity between lineages of Maf and that of Mtb.

As has been detailed above, genomics and bioinformatics, though relatively new in biomedical disciplines, they are very useful tools for diseases surveillance and have a role to play in 
the control of infectious diseases including tuberculosis. WGS of MTBC can be used in routine care settings for species identification, determination of drug resistance profiles and to complement epidemiological source investigation. Although few research works have used these tools in West-Africa to date, they are increasingly being used especially in universities and research institutions. Nevertheless, due to cost and infrastructural as well as expertise demands, its usefulness has not been felt in public health intervention programs. Some implementation challenges include funding for infrastructure as well as expertise for WGS in many research settings and even greater challenges in the context of the clinical settings. Major efforts need to be made in building human capacity as well as infrastructure investment in national public health reference laboratories to improve health care in high burdened countries. Moreover, the cost of WGS is coming down drastically and there are available simplified/portable platforms such as the minion that is field friendly and less expensive. The establishment of WGS in routine settings such as regional and national public health reference laboratories of the national health system will need to be done in a way that is relevant to the local health priorities. It is anticipated that current capacity building being championed by programs such as the African Centers of Excellence being financed through World Bank Loans, DELTAS financed by Wellcome Trust through the African Academy of Sciences will enhance implementation of WGS as part of routine health service surveillance activities, which improve health delivery in West African countries such as Ghana. This is evidenced in the contribution of some of the centers in the sequencing efforts of SARS-CoV 2 within the region (187).

The highest incidence and impact of antimicrobial resistance (AMR) is experienced in resource-poor settings (188). Underlying factors promoting AMR include misuse of antimicrobials, lower access to alternative antibiotics and the prevalence of multidrug-resistant bacterial strains (189). The slow growth nature of the MTBC negatively impacts the use of culture for routine surveillance of DR, hence, making molecular detection the better option. Routine and systematic surveillance of AMR infections is key to inform policy decisions and public health interventions to counter AMR. WGS and

\section{REFERENCES}

1. Daniel TM. The history of tuberculosis. Respir Med. (2006) 100:186270. doi: 10.1016/j.rmed.2006.08.006

2. Daniel TM. Robert Koch and the pathogenesis of tuberculosis. Int J Tuberc Lung Dis. (2005) 9:1181-2.

3. WHO. Global Tuberculosis Report. (2018). Available online at: http://www. who.int/tb/publications/global_report/en/ (accessed September 26, 2019).

4. WHO. Global Tuberculosis Report. (2020). Available online at: https://www. who.int/teams/global-tuberculosis-programme/data

5. WHO. Gear Up to End TB: Introducing the End TB Strategy. (2015). Available online at: https://www.who.int/tb/End_TB_brochure.pdf (accessed February 2, 2019).

6. Brosch R, Gordon SV, Marmiesse M, Brodin P, Buchrieser $\mathrm{C}$, Eiglmeier $\mathrm{K}$, et al. A new evolutionary scenario for the Mycobacterium tuberculosis. complex. Proc Natl Acad Sci USA. (2002) 99:3684-9. doi: 10.1073/pnas.052548299 targeted sequencing offer the opportunity for the identification of the causative pathogen, to understand the genetic basis of resistance, as well as pathogen evolution and population dynamics at different spatial and temporal scales. It also offers the opportunity to probe the whole genome to detect not only susceptibility to a single antibiotic but multiple antibiotics at the same time. It is envisaged that potable sequencing platforms will be established at least in national and supra national reference laboratories within the region to support the DR surveillance efforts.

The use of WGS has a great prospect toward improved individual case management of infectious and noncommunicable diseases. Advancement in simplified, high-throughput genomic technologies will in future assist West-Africa to sequence the whole exome or genome of a person at a price that is affordable for some health-care systems. More services based on these technologies will enhance host-directed therapies appropriate to individual patients with probing limited to analysis of specific (sets of) genes of clinical value $(190,191)$. WGS in future will be useful in West-Africa for evaluation of interventions such as vaccination for preventive policies through enhanced assessment of disease and drug resistance transmission dynamics. Furthermore, it will improve pathogen detection, especially with the emergence of new and un-culturable infections as well as biological risk prediction.

\section{AUTHOR CONTRIBUTIONS}

All authors listed have made a substantial, direct and intellectual contribution to the work, and approved it for publication.

\section{FUNDING}

DY-M is a GSK-EDCTP Senior Fellow (TMA.2017.GSF.1942TB-DM).

\section{ACKNOWLEDGMENTS}

We are grateful to Coscolla et al., for granting us the permission to reuse their figures in this manuscript.
7. Huard RC, Lazzarini LC, Butler WR, van Soolingen D, Ho JL. PCR-based method to differentiate the subspecies of the Mycobacterium tuberculosis complex on the basis of genomic deletions. J Clin Microbiol. (2003) 41:163750. doi: 10.1128/JCM.41.4.1637-1650.2003

8. Mostowy S, Cousins D, Brinkman J, Aranaz A, Behr MA. Genomic deletions suggest a phylogeny for the Mycobacterium tuberculosis complex. J Infect Dis. (2002) 186:74-80. doi: 10.1086/341068

9. van Ingen J, Rahim Z, Mulder A, Boeree MJ, Simeone R, Brosch $\mathrm{R}$, et al. Characterization of Mycobacterium orygis as M. tuberculosis complex subspecies. Emerg Infect Dis. (2012) 18:653-5. doi: 10.3201/eid1804. 110888

10. Cousins DV, Bastida R, Cataldi A, Quse V, Redrobe S, Dow S, et al. Tuberculosis in seals caused by a novel member of the Mycobacterium tuberculosis complex: Mycobacterium pinnipedii sp. nov. Int J Syst Evol Microbiol. (2003) 53:1305-1314. doi: 10.1099/ijs.0.02401-0

11. Frota CC, Hunt DM, Buxton RS, Rickman L, Hinds J, Kremer K, et al. Genome structure in the vole bacillus, Mycobacterium microti, a member 
of the Mycobacterium tuberculosis complex with a low virulence for humans. Microbiology. (2004) 150:1519-27. doi: 10.1099/mic.0.26660-0

12. Gagneux S, Small PM. Global phylogeography of Mycobacterium tuberculosis and implications for tuberculosis product development. Lancet Infect Dis. (2007) 7:328-37. doi: 10.1016/S1473-3099(07)70108-1

13. Garnier T, Eiglmeier K, Camus JC, Medina N, Mansoor H, Pryor M, et al. The complete genome sequence of Mycobacterium bovis. Proc Natl Acad Sci USA. (2003) 100:7877-82. doi: 10.1073/pnas.1130426100

14. Coscolla M, Lewin A, Metzger S, Maetz-Rennsing K, Calvignac-Spencer S, Nitsche A, et al. (2013, Jun). Novel mycobacterium tuberculosis complex isolate from a wild chimpanzee. Emerg. Infect. Dis. 19:969-76. doi: 10.3201/eid1906.121012

15. Smith NH, Gordon SV, de la Rua-Domenech R, Clifton-Hadley RS, Hewinson RG. (2006, Sep). Bottlenecks and broomsticks: the molecular evolution of Mycobacterium bovis. Nat Rev Microbiol. 4:670-81. doi: $10.1038 /$ nrmicrol472

16. Wells AQ, Oxon DM. Tuberculosis in wild voles. Lancet. (1937) 139 :.

17. Addo K, Owusu-Darko K, Yeboah-Manu D, Caulley P, Minamikawa M, Bonsu F, et al. Mycobacterial species causing pulmonary tuberculosis at the korle bu teaching hospital, accra, ghana. Ghana Med J. (2007) 41:527. doi: $10.4314 /$ gmj.v41i2.55293

18. Asante-Poku A, Otchere ID, Osei-Wusu S, Sarpong E, Baddoo A, Forson A, et al. Molecular epidemiology of Mycobacterium africanum in Ghana. BMC Infect Dis. (2016) 16:385. doi: 10.1186/s12879-016-1725-6

19. Yeboah-Manu D, Asare P, Asante-Poku A, Otchere ID, Osei-Wusu S, Danso E, et al. Spatio-temporal distribution of Mycobacterium tuberculosis complex strains in Ghana. PLoS ONE. (2016) 11:e0161892. doi: 10.1371/journal.pone.0161892

20. Davenne T, McShane $H$. Why don't we have an effective tuberculosis vaccine yet? Expert RevVaccines. (2016) 15:100913. doi: $10.1586 / 14760584.2016 .1170599$

21. Zwerling A, Behr MA, Verma A, Brewer TF, Menzies D, Pai M. The BCG World Atlas: a database of global BCG vaccination policies and practices. PLoS Med. (2011) 8:e1001012. doi: 10.1371/journal.pmed.1001012

22. Owolabi OA, Jallow AO, Jallow M, Sowe G, Jallow R, Genekah MD, et al. Delay in the diagnosis of pulmonary tuberculosis in the Gambia, West Africa: a cross-sectional study. Int J Infect Dis. (2020) 101:1026. doi: 10.1016/j.ijid.2020.09.029

23. NTP. World TB Day Press Release. Ghana: National Tuberculosis Control Program (NTP) - (2019).

24. Togun TO, Egere U, Sillah AK, Ayorinde A, Mendy F, Tientcheu L, et al. Contribution of $\mathrm{Xpert}(\mathrm{R}) \mathrm{MTB} / \mathrm{RIF}$ to the diagnosis of pulmonary tuberculosis among TB-exposed children in the Gambia. Int J Tuberc Lung Dis. (2015) 19:1091-7, i-ii. doi: 10.5588/ijtld.15.0228

25. Zumla A, Abubakar I, Raviglione M, Hoelscher M, Ditiu L, McHugh TD, et al. Drug-resistant tuberculosis-current dilemmas, unanswered questions, challenges, and priority needs. J Infect Dis. (2012) 205(Suppl. 2):S22840. doi: 10.1093/infdis/jir858

26. WHO. Guidelines on the Management of Latent Tuberculosis Infection. (2015). Available online at: https://www.who.int/tb/publications/ltbi_ document_page/en/ (accessed December 28, 2018).

27. Ekaza E, N'Guessan RK, Kacou-N'Douba A, Aka N, Kouakou J, Le Vacon F, et al. Emergence in Western African countries of MDR-TB, focus on Côte d'Ivoire. Biomed Res Int. (2013) 2013:426709. doi: 10.1155/2013/426709

28. Gehre F, Otu J, Kendall L, Forson A, Kwara A, Kudzawu S, et al. The emerging threat of pre-extensively drug-resistant tuberculosis in West Africa: preparing for large-scale tuberculosis research and drug resistance surveillance. BMC Med. (2016) 14:160. doi: 10.1186/s12916-0160704-5

29. Osei-Wusu S, Amo Omari M, Asante-Poku A, Darko Otchere I, Asare $\mathrm{P}$, Forson A, et al. Second-line anti-tuberculosis drug resistance testing in Ghana identifies the first extensively drug-resistant tuberculosis case. Infect Drug Resist. (2018) 11:239-46. doi: 10.2147/IDR.S152720

30. Otu J, Gehre F, Zingue D, Kudzawu S, Forson A, Mane M, et al. MultidrugResistant Tuberculosis (Mdr-Tb): an emerging problem in West Africa. BMJ Global Health. (2017) 2:A32-3. doi: 10.1136/bmjgh-2016-000260.85

31. Anderson LF, Tamne S, Brown T, Watson JP, Mullarkey C, Zenner D, et al. Transmission of multidrug-resistant tuberculosis in the UK: a cross-sectional molecular and epidemiological study of clustering and contact tracing. Lancet Infect Dis. (2014) 14:406-15. doi: 10.1016/S1473-3099(14)70022-2

32. Barnes PF, Cave MD. Molecular epidemiology of tuberculosis. N Engl J Med. (2003) 349:1149-56. doi: 10.1056/NEJMra021964

33. Hamblion EL, Le Menach A, Anderson LF, Lalor MK, Brown T, Abubakar I, et al. Recent TB transmission, clustering and predictors of large clusters in London, 2010-2012: results from first 3 years of universal MIRUVNTR strain typing. Thorax. (2016) 71:749-56. doi: 10.1136/thoraxjnl-20 14-206608

34. Huard RC, Fabre M, de Haas P, Lazzarini LC, van Soolingen D, Cousins $\mathrm{D}$, et al. Novel genetic polymorphisms that further delineate the phylogeny of the Mycobacterium tuberculosis complex. J Bacteriol. (2006) 188:427187. doi: 10.1128/JB.01783-05

35. Achtman M. Evolution, population structure, and phylogeography of genetically monomorphic bacterial pathogens. Annu Rev Microbiol. (2008) 62:53-70. doi: 10.1146/annurev.micro.62.081307.162832

36. Kamerbeek J, Schouls L, Kolk A, van Agterveld M, van Soolingen D, Kuijper $\mathrm{S}$, et al. Simultaneous detection and strain differentiation of Mycobacterium tuberculosis for diagnosis and epidemiology. J Clin Microbiol. (1997) 35:90714. doi: $10.1128 / \mathrm{jcm} \cdot 35.4 .907-914.1997$

37. van Embden JD, Cave MD, Crawford JT, Dale JW, Eisenach KD, Gicquel B, et al. Strain identification of Mycobacterium tuberculosis by DNA fingerprinting: recommendations for a standardized methodology. J Clin Microbiol. (1993) 31:406-9. doi: 10.1128/jcm.31.2.406-409.1993

38. Supply P, Lesjean S, Savine E, Kremer K, van Soolingen D, Locht C. Automated high-throughput genotyping for study of global epidemiology of Mycobacterium tuberculosis based on mycobacterial interspersed repetitive units. J Clin Microbiol. (2001) 39:3563-71. doi: 10.1128/JCM.39.10.3563-3571.2001

39. Comas I, Coscolla M, Luo T, Borrell S, Holt KE, Kato-Maeda M, et al. Out-ofAfrica migration and Neolithic coexpansion of Mycobacterium tuberculosis with modern humans. Nat Genet. (2013) 45:1176-82. doi: 10.1038/ng.2744

40. Coscolla M, Gagneux S, Menardo F, Loiseau C, Ruiz-Rodriguez P, Borrell S, et al. Phylogenomics of Mycobacterium africanum reveals a new lineage and a complex evolutionary history. Microb Genom. (2021) 7:000477. doi: 10.1099/mgen.0.000477

41. Schork NJ, Fallin D, Lanchbury JS. Single nucleotide polymorphisms and the future of genetic epidemiology. Clin Genet. (2000) 58:25064. doi: 10.1034/j.1399-0004.2000.580402.x

42. Gagneux S, DeRiemer K, Van T, Kato-Maeda M, de Jong BC, Narayanan S, et al. Variable host-pathogen compatibility in Mycobacterium tuberculosis. Proc Natl Acad Sci USA. (2006) 103:2869-73. doi: 10.1073/pnas.0511240103

43. Comas I, Homolka S, Niemann S, Gagneux S. Genotyping of genetically monomorphic bacteria: DNA sequencing in Mycobacterium tuberculosis highlights the limitations of current methodologies. PLoS ONE. (2009) 4:e7815. doi: 10.1371/journal.pone. 0007815

44. Kargarpour Kamakoli M, Khanipour S, Hadifar S, Ghajavand H, Farmanfarmaei G, Fateh A, et al. Challenge in direct Spoligotyping of Mycobacterium tuberculosis: a problematic issue in the region with high prevalence of polyclonal infections. BMC Res Notes. (2018) 11:486. doi: 10.1186/s13104-018-3579-z

45. Asare P, Asante-Poku A, Prah DA, Borrell S, Osei-Wusu S, Otchere ID, et al. Reduced transmission of Mycobacterium africanum compared to Mycobacterium tuberculosis in urban West Africa. Int J Infect Dis. (2018) 73:30-42. doi: 10.1016/j.ijid.2018.05.014

46. Norheim G, Seterelv S, Arnesen TM, Mengshoel AT, Tonjum T, Ronning JO, et al. Tuberculosis outbreak in an educational institution in Norway. J Clin Microbiol. (2017) 55:1327-33. doi: 10.1128/JCM. 01152-16

47. Streit E, Baboolal S, Akpaka PE, Millet J, Rastogi N. Finer characterization of Mycobacterium tuberculosis using spoligotyping and 15-loci MIRU-VNTRs reveals phylogeographical specificities of isolates circulating in Guyana and Suriname. Infect Genetic Evolut. (2015) 30:114-9. doi: 10.1016/j.meegid.2014.12.015

48. Vluggen C, Soetaert K, Groenen G, Wanlin M, Spitaels M, Arrazola de Onate $\mathrm{W}$, et al. Molecular epidemiology of Mycobacterium tuberculosis complex in Brussels, 2010-2013. PLoS ONE. (2017) 12:e0172554. doi: 10.1371/journal.pone.0172554 
49. Zamani S, Haeili M, Nasiri MJ, Imani Fooladi AA, Javadpour S, Feizabadi MM. Genotyping of Mycobacterium tuberculosis Isolates from hormozgan province of Iran based on 15-Locus MIRU-VNTR and spoligotyping. Int J Bacteriol. (2016) 2016:7146470. doi: 10.1155/2016/7146470

50. Dong H, Shi L, Zhao X, Sang B, Lv B, Liu Z, et al. Genetic diversity of Mycobacterium tuberculosis isolates from Tibetans in Tibet, China. PLoS ONE. (2012) 7:e33904. doi: 10.1371/journal.pone.0033904

51. Murase Y, Mitarai S, Sugawara I, Kato S, Maeda S. Promising loci of variable numbers of tandem repeats for typing Beijing family Mycobacterium tuberculosis. J Med Microbiol. (2008) 57:873-80. doi: 10.1099/jmm.0.47564-0

52. Shamputa IC, Lee J, Allix-Beguec C, Cho EJ, Lee JI, Rajan V, et al. Genetic diversity of Mycobacterium tuberculosis isolates from a tertiary care tuberculosis hospital in South Korea. J Clin Microbiol. (2010) 48:38794. doi: 10.1128/JCM.02167-09

53. Asare P, Otchere ID, Bedeley E, Brites D, Loiseau C, Baddoo NA, et al. Whole genome sequencing and spatial analysis identifies recent tuberculosis transmission hotspots in Ghana. Front Med. (2020) 7:161. doi: 10.3389/fmed.2020.00161

54. Schurch AC, Kremer K, Daviena O, Kiers A, Boeree MJ, Siezen RJ, et al. High-resolution typing by integration of genome sequencing data in a large tuberculosis cluster. J Clin Microbiol. (2010) 48:34036. doi: 10.1128/JCM.00370-10

55. Bryant JM, Schurch AC, van Deutekom H, Harris SR, de Beer JL, de Jager V, et al. Inferring patient to patient transmission of Mycobacterium tuberculosis from whole genome sequencing data. BMC Infect Dis. (2013) 13:110. doi: 10.1186/1471-2334-13-110

56. Casali N, Nikolayevskyy V, Balabanova Y, Harris SR, Ignatyeva O, Kontsevaya I, et al. Evolution and transmission of drug-resistant tuberculosis in a Russian population. Nat Genet. (2014) 46:279-86. doi: 10.1038/ng.2878

57. Casali N, Nikolayevskyy V, Balabanova Y, Ignatyeva O, Kontsevaya I, Harris SR, et al. Microevolution of extensively drug-resistant tuberculosis in Russia. Genome Res. (2012) 22:735-45. doi: 10.1101/gr.128678.111

58. Comas I, Borrell S, Roetzer A, Rose G, Malla B, Kato-Maeda M, et al. Wholegenome sequencing of rifampicin-resistant Mycobacterium tuberculosis strains identifies compensatory mutations in RNA polymerase genes. Nat Genet. (2011) 44:106-10. doi: 10.1038/ng.1038

59. Koser CU, Bryant JM, Parkhill J, Peacock SJ. Consequences of whiB7 (Rv3197A) mutations in Beijing genotype isolates of the Mycobacterium tuberculosis complex. Antimicrob Agents Chemother. (2013) 57:3461. doi: 10.1128/AAC.00626-13

60. Blouin Y, Hauck Y, Soler C, Fabre M, Vong R, Dehan C, et al. Significance of the identification in the horn of africa of an exceptionally deep branching Mycobacterium tuberculosis clade. PLoS ONE. (2012) 7:e52841. doi: 10.1371/journal.pone.0052841

61. Ngabonziza JCS, Loiseau C, Marceau M, Jouet A, Menardo F, Tzfadia $\mathrm{O}$, et al. A sister lineage of the Mycobacterium tuberculosis complex discovered in the African Great Lakes region. Nat Commun. (2020) 11:2917. doi: 10.1038/s41467-020-16626-6

62. Goig GA, Torres-Puente M, Mariner-Llicer C, Villamayor LM, ChinerOms Á, Gil-Brusola A, et al. Towards next-generation diagnostics for tuberculosis: identification of novel molecular targets by large-scale comparative genomics. Bioinformatics. (2020) 36:985-9. doi: 10.1101/569384

63. Hijikata M, Keicho N, Duc LV, Maeda S, Hang NTL, Matsushita I, et al. Spoligotyping and whole-genome sequencing analysis of lineage 1 strains of Mycobacterium tuberculosis in Da Nang, Vietnam. PLoS ONE. (2017) 12:e0186800. doi: 10.1371/journal.pone.0186800

64. Malm S, Linguissi LS, Tekwu EM, Vouvoungui JC, Kohl TA, Beckert P, et al. New Mycobacterium tuberculosis complex sublineage, Brazzaville, Congo. Emerging Infect Dis. (2017) 23:423-9. doi: 10.3201/eid2303. 160679

65. Rutaihwa LK, Sasamalo M, Jaleco A, Hella J, Kingazi A, Kamwela L, et al. Insights into the genetic diversity of Mycobacterium tuberculosis in Tanzania. PLoS ONE. (2019) 14:e0206334. doi: 10.1371/journal.pone. 0206334

66. Shuaib YA, Khalil EAG, Wieler LH, Schaible UE, Bakheit MA, MohamedNoor SE, et al. Mycobacterium tuberculosis complex lineage 3 as causative agent of pulmonary tuberculosis, Eastern Sudan(1). Emerg Infect Dis. (2020) 26:427-36. doi: 10.3201/eid2603.191145
67. de Jong BC, Antonio M, Gagneux S. Mycobacterium africanum-review of an important cause of human tuberculosis in West Africa. PLoS Negl Trop Dis. (2010) 4:e744. doi: 10.1371/journal.pntd.0000744

68. Asante-Poku A, Yeboah-Manu D, Otchere ID, Aboagye SY, Stucki $\mathrm{D}$, Hattendorf $\mathrm{J}$, et al. Mycobacterium africanum is associated with patient ethnicity in Ghana. PLoS Negl Trop Dis. (2015) 9:e3370. doi: 10.1371/journal.pntd.0003370

69. Reed MB, Pichler VK, McIntosh F, Mattia A, Fallow A, Masala S, et al. Major Mycobacterium tuberculosis lineages associate with patient country of origin. J Clin Microbiol. (2009) 47:1119-28. doi: 10.1128/JCM.02142-08

70. Stucki D, Brites D, Jeljeli L, Coscolla M, Liu Q, Trauner A, et al. Mycobacterium tuberculosis lineage 4 comprises globally distributed and geographically restricted sublineages. Nat Genet. (2016) 48:153543. doi: $10.1038 / \mathrm{ng} .3704$

71. Brynildsrud OB, Pepperell CS, Suffys P, Grandjean L, Monteserin J, Debech N, et al. (2018). Global expansion of Mycobacterium tuberculosis lineage 4 shaped by colonial migration and local adaptation. Sci Adv. 4:eaat. doi: 10.1126/sciadv.aat5869

72. Cole ST, Brosch R, Parkhill J, Garnier T, Churcher C, Harris D, et al. Deciphering the biology of Mycobacterium tuberculosis from the complete genome sequence. Nature. (1998) 393:537-44. doi: 10.1038/31159

73. Serres MH, Gopal S, Nahum LA, Liang P, Gaasterland T, Riley M. A functional update of the Escherichia coli K-12 genome. Genome Biol. (2001) 2:Research0035. doi: 10.1186/gb-2001-2-9-research0035

74. Hershberg R, Lipatov M, Small PM, Sheffer H, Niemann S, Homolka $\mathrm{S}$, et al. High functional diversity in Mycobacterium tuberculosis driven by genetic drift and human demography. PLoS Biol. (2008) 6:e311. doi: 10.1371/journal.pbio.0060311

75. Blouin Y, Cazajous G, Dehan C, Soler C, Vong R, Hassan MO, et al. Progenitor "Mycobacterium canettii" clone responsible for lymph node tuberculosis epidemic, Djibouti. Emerg Infect Dis. (2014) 20:218. doi: 10.3201/eid2001.130652

76. Coscolla M, Gagneux S. Consequences of genomic diversity in Mycobacterium tuberculosis. Semin Immunol. (2014) 26:43144. doi: 10.1016/j.smim.2014.09.012

77. Ioerger TR, Feng Y, Ganesula K, Chen X, Dobos KM, Fortune S, et al. Variation among genome sequences of $\mathrm{H} 37 \mathrm{Rv}$ strains of Mycobacterium tuberculosis from multiple laboratories. J Bacteriol. (2010) 192:364553. doi: 10.1128/JB.00166-10

78. Supply P, Marceau M, Mangenot S, Roche D, Rouanet C, Khanna V, et al. Genomic analysis of smooth tubercle bacilli provides insights into ancestry and pathoadaptation of Mycobacterium tuberculosis. Nat Genet. (2013) 45:172-9. doi: 10.1038/ng.2517

79. Sreevatsan S, Pan X, Stockbauer KE, Connell ND, Kreiswirth BN, Whittam TS, et al. Restricted structural gene polymorphism in the Mycobacterium tuberculosis complex indicates evolutionarily recent global dissemination. Proc Natl Acad Sci USA. (1997) 94:9869-74. doi: 10.1073/pnas.94.18.9869

80. Coscolla M, Gagneux S. Does M. Tuberculosis genomic diversity explain disease diversity? Drug discovery today. Dis Mechan. (2010) 7:e4359. doi: 10.1016/j.ddmec.2010.09.004

81. Gehre F, Otu J, DeRiemer K, de Sessions PF, Hibberd ML, Mulders W, et al. Deciphering the growth behaviour of Mycobacterium africanum. PLoS Negl Trop Dis. (2013) 7:e2220. doi: 10.1371/journal.pntd.0002220

82. Krishnan N, Malaga W, Constant P, Caws M, Tran TH, Salmons J, et al. Mycobacterium tuberculosis lineage influences innate immune response and virulence and is associated with distinct cell envelope lipid profiles. PLoS ONE. (2011) 6:e23870. doi: 10.1371/journal.pone.0023870

83. Ofori-Anyinam B, Kanuteh F, Agbla SC, Adetifa I, Okoi C, Dolganov $\mathrm{G}$, et al. Impact of the Mycobaterium africanum West Africa 2 Lineage on TB diagnostics in West Africa: decreased sensitivity of rapid identification tests in the Gambia. PLoS Negl Trop Dis. (2016) 10:e0004801. doi: 10.1371/journal.pntd.0004801

84. Otchere ID, Coscollá M, Sánchez-Busó L, Asante-Poku A, Brites D, Loiseau $\mathrm{C}$, et al. Comparative genomics of Mycobacterium africanum Lineage 5 and Lineage 6 from Ghana suggests distinct ecological niches. Sci Rep. (2018) 8:11269. doi: 10.1038/s41598-018-29620-2

85. Sanoussi CN, de Jong BC, Odoun M, Arekpa K, Ali Ligali M, Bodi O, et al. Low sensitivity of the MPT64 identification test to detect lineage 5 of 
the Mycobacterium tuberculosis complex. J Med Microbiol. (2018) 67:171827. doi: $10.1099 / \mathrm{jmm} .0 .000846$

86. Sarkar R, Lenders L, Wilkinson KA, Wilkinson RJ, Nicol MP. Modern lineages of Mycobacterium tuberculosis exhibit lineage-specific patterns of growth and cytokine induction in human monocyte-derived macrophages. PLoS ONE. (2012) 7:e43170. doi: 10.1371/journal.pone.0043170

87. Winglee K, Manson McGuire A, Maiga M, Abeel T, Shea T, Desjardins CA, et al. Whole genome sequencing of Mycobacterium africanum Strains from mali provides insights into the mechanisms of geographic restriction. PLoS Negl Trop Dis. (2016) 10:e0004332. doi: 10.1371/journal.pntd.0004332

88. Bentley SD, Comas I, Bryant JM, Walker D, Smith NH, Harris SR, et al. The genome of Mycobacterium africanum West African 2 reveals a lineagespecific locus and genome erosion common to the M. tuberculosis complex. PLoS Neglected Trop Dis. (2012) 6:e1552. doi: 10.1371/journal.pntd.0001552

89. Colangeli R, Helb D, Sridharan S, Sun J, Varma-Basil M, Hazbón MH, et al. The Mycobacterium tuberculosis iniA gene is essential for activity of an efflux pump that confers drug tolerance to both isoniazid and ethambutol. Mol Microbiol. (2005) 55:1829-40. doi: 10.1111/j.1365-2958.2005.04510.x

90. Koivula T, Svenson SB, Källenius G. The mtp40 gene is not present in Mycobacterium bovis. Tuberculosis. (2002) 82:1835. doi: 10.1054/tube.2002.0338

91. Sinha P, Prakash P, Patne SC, Anupurba S, Gupta S, Srivastava GN. Performance of nested multiplex PCR assay targeting MTP40 and IS6110 gene sequences for the diagnosis of tubercular lymphadenitis. J Microbiol. (2017) 55:63-7. doi: 10.1007/s12275-017-6127-y

92. Bogaert D, van der Valk P, Ramdin R, Sluijter M, Monninkhof E, Hendrix R, et al. Host-pathogen interaction during pneumococcal infection in patients with chronic obstructive pulmonary disease. Infect Immun. (2004) 72:81823. doi: 10.1128/IAI.72.2.818-823.2004

93. Buboltz AM, Nicholson TL, Karanikas AT, Preston A, Harvill ET. Evidence for horizontal gene transfer of two antigenically distinct $\mathrm{O}$ antigens in Bordetella bronchiseptica. Infect Immun. (2009) 77:324957. doi: 10.1128/IAI.01448-08

94. Lipsitch M. Bacterial vaccines and serotype replacement: lessons from Haemophilus influenzae and prospects for Streptococcus pneumoniae. Emerging Infect Dis. (1999) 5:336-45. doi: 10.3201/eid0503.990304

95. Madoff LC, Michel JL, Gong EW, Kling DE, Kasper DL. Group B streptococci escape host immunity by deletion of tandem repeat elements of the alpha C protein. Proc Natl Acad Sci USA. (1996) 93:41316. doi: 10.1073/pnas.93.9.4131

96. Schouls L, van der Heide H, Witteveen S, Zomer B, van der Ende A, Burger $M$, et al. Two variants among Haemophilus influenzae serotype b strains with distinct bcs4, hcsA and hcsB genes display differences in expression of the polysaccharide capsule. BMC Microbiol. (2008) 8:35. doi: 10.1186/1471-2180-8-35

97. Spratt BG, Greenwood BM. Prevention of pneumococcal disease by vaccination: does serotype replacement matter? Lancet. (2000) 356:12101. doi: 10.1016/S0140-6736(00)02779-3

98. de Jong BC, Hill PC, Aiken A, Awine T, Antonio M, Adetifa IM, et al. Progression to active tuberculosis, but not transmission, varies by Mycobacterium tuberculosis lineage in the Gambia. J Infect Dis. (2008) 198:1037-43. doi: 10.1086/591504

99. Huang CC, Chu AL, Becerra MC, Galea JT, Calderon R, Contreras C, et al. Mycobacterium tuberculosis Beijing lineage and risk for tuberculosis in child household contacts, Peru. Emerging Infect Dis. (2020) 26:56878. doi: 10.3201/eid2603.191314

100. Forrellad MA, Klepp LI, Gioffre A, Sabioy Garcia J, Morbidoni HR, de la Paz Santangelo M, et al. Virulence factors of the Mycobacterium tuberculosis complex. Virulence. (2013) 4:3-66. doi: 10.4161/viru.22329

101. Nunes-Alves C, Booty MG, Carpenter SM, Jayaraman P, Rothchild AC, Behar SM. In search of a new paradigm for protective immunity to TB. Nat Rev Microbiol. (2014) 12:289-99. doi: 10.1038/nrmicro3230

102. López B, Aguilar D, Orozco H, Burger M, Espitia C, Ritacco V, et al. A marked difference in pathogenesis and immune response induced by different Mycobacterium tuberculosis genotypes. Clin Exp Immunol. (2003) 133:30-7. doi: 10.1046/j.1365-2249.2003.02171.x

103. Portevin D, Gagneux S, Comas I, Young D. Human macrophage responses to clinical isolates from the Mycobacterium tuberculosis complex discriminate between ancient and modern lineages. PLoS Pathog. (2011) 7:e1001307. doi: 10.1371/journal.ppat.1001307

104. Bold TD, Davis DC, Penberthy KK, Cox LM, Ernst JD, de Jong BC. Impaired fitness of Mycobacterium africanum despite secretion of ESAT-6.J Infect Dis. (2012) 205:984-90. doi: 10.1093/infdis/jir883

105. Gehre F, Antonio M, Faihun F, Odoun M, Uwizeye C, de Rijk P, et al. The first phylogeographic population structure and analysis of transmission dynamics of $M$. africanum West African 1-combining molecular data from Benin, Nigeria and Sierra Leone. PLoS ONE. (2013) 8:e77000. doi: 10.1371/journal.pone.0077000

106. Meyer CG, Scarisbrick G, Niemann S, Browne ENL, Chinbuah MA, Gyapong J, et al. Pulmonary tuberculosis: Virulence of Mycobacterium africanum and relevance in HIV co-infection. Tuberculosis. (2008) 88:4829. doi: 10.1016/j.tube.2008.05.004

107. Fleischmann RD, Alland D, Eisen JA, Carpenter L, White O, Peterson J, et al. Whole-genome comparison of Mycobacterium tuberculosis clinical and laboratory strains. J Bacteriol. (2002) 184:5479-90. doi: 10.1128/JB.184.19.5479-5490.2002

108. Mostowy S, Onipede A, Gagneux S, Niemann S, Kremer K, Desmond EP, et al. Genomic analysis distinguishes Mycobacterium africanum. J Clin Microbiol. (2004) 42:3594-9. doi: 10.1128/JCM.42.8.3594-3599.2004

109. Tsolaki AG, Hirsh AE, DeRiemer K, Enciso JA, Wong MZ, Hannan M, et al. Functional and evolutionary genomics of Mycobacterium tuberculosis: insights from genomic deletions in 100 strains. Proc Natl Acad Sci USA. (2004) 101:4865-70. doi: 10.1073/pnas.0305634101

110. Guinn KM, Hickey MJ, Mathur SK, Zakel KL, Grotzke JE, Lewinsohn DM, et al. Individual RD1-region genes are required for export of ESAT-6/CFP10 and for virulence of Mycobacterium tuberculosis. Mol Microbiol. (2004) 51:359-70. doi: 10.1046/j.1365-2958.2003.03844.x

111. Pym AS, Brodin P, Brosch R, Huerre M, Cole ST. Loss of RD1 contributed to the attenuation of the live tuberculosis vaccines Mycobacterium bovis BCG and Mycobacterium microti. Mol Microbiol. (2002) 46:70917. doi: 10.1046/j.1365-2958.2002.03237.x

112. Stanley SA, Raghavan S, Hwang WW, Cox JS. Acute infection and macrophage subversion by Mycobacterium tuberculosis require a specialized secretion system. Proc Natl Acad Sci USA. (2003) 100:13001-6. doi: 10.1073/pnas.2235593100

113. Otchere ID, Harris SR, Busso SL, Asante-Poku A, Osei-Wusu S, Koram $\mathrm{K}$, et al. The First population structure and comparative genomics analysis of Mycobacterium africanum strains from Ghana reveals higher diversity of Lineage. Int J Mycobacteriol. (2016) 5:S801. doi: 10.1016/j.ijmyco.2016.09.051

114. Otchere ID. Comparative genomic analysis of Mycobacterium tuberculosis complex strains from Ghana [thesis]. PhD. Thesis published in University of Ghana digital collection (2017). Available online at: http://ugspace.ug.edu. gh/handle/123456789/24762 (accessed May 5, 2021).

115. Horvat RT. Gamma interferon assays used in the diagnosis of tuberculosis. Clin Vaccine Immunol. (2015) 22:845. doi: 10.1128/CVI.00199-15

116. Brandt L, Elhay M, Rosenkrands I, Lindblad EB, Andersen P. ESAT6 subunit vaccination against Mycobacterium tuberculosis. Infect Immun. (2000) 68:791-5. doi: 10.1128/IAI.68.2.791-795.2000

117. Kim WS, Kim H, Kwon KW, Cho SN, Shin SJ. Immunogenicity and vaccine potential of InsB, an ESAT-6-Like antigen identified in the highly virulent Mycobacterium tuberculosis Beijing K strain. Front Microbiol. (2019) 10:220. doi: $10.3389 /$ fmicb. 2019.00220

118. Gautam SS, Haug G, Cooley LA, Mac Aogain M and O'Toole RF. Intercontinental translocation of latent multidrug-resistant tuberculosis to Australia demonstrated by whole genome sequencing. Med J Australia. (2019) 210:236-231. doi: 10.5694/mja2.50044

119. Gautam SS, Mac Aogain M, Cooley LA, Haug G, Fyfe JA, Globan M, et al. Molecular epidemiology of tuberculosis in Tasmania and genomic characterisation of its first known multi-drug resistant case. PLOS ONE. (2018) 13:e0192351. doi: 10.1371/journal.pone.0192351

120. Seraphin MN, Lauzardo M, Doggett RT, Zabala J, Morris JG Jr, Blackburn JK. Spatiotemporal clustering of Mycobacterium tuberculosis complex genotypes in florida: genetic diversity segregated by country of birth. PLoS ONE. (2016) 11:e0153575. doi: 10.1371/journal.pone.01 53575 
121. Asare P, Osei-Wusu S, Baddoo NA, Bedeley E, Otchere ID, Brites D, et al. Genomic epidemiological analysis identifies high relapse among individuals with recurring tuberculosis and provides evidence of recent householdrelated transmission of tuberculosis in Ghana. Int I Infect Dis. (2021) 106:1322. doi: $10.1016 /$ j.ijid.2021.02.110

122. Shanmugam S, Bachmann NL, Martinez E, Menon R, Narendran G, Narayanan S, et al. Whole genome sequencing based differentiation between re-infection and relapse in Indian patients with tuberculosis recurrence, with and without HIV co-infection. Int $J$ Infect Dis. (2021). doi: 10.1016/j.ijid.2021.03.020. [Epub ahead of print].

123. Varghese B, al-Omari R, Grimshaw C, Al-Hajoj S. Endogenous reactivation followed by exogenous re-infection with drug resistant strains, a new challenge for tuberculosis control in Saudi Arabia. Tuberculosis. (2013) 93:246-249. doi: 10.1016/j.tube.2012.12.001

124. van Soolingen D, Kremer K, Vynycky E. New perspectives in the molecular epidemiology of tuberculosis. In: Mycobacteria and TB. Vol. 2. Karger Publishers (2003). p. 17-45. doi: 10.1159/000066887

125. Jagielski $\mathrm{T}$, van Ingen J, Rastogi $\mathrm{N}$, Dziadek J, Mazur PK, Bielecki J. Current methods in the molecular typing of Mycobacterium tuberculosis and other mycobacteria. Biomed Res Int. (2014) 2014:645802. doi: 10.1155/2014/645802

126. Jamieson FB, Teatero S, Guthrie JL, Neemuchwala A, Fittipaldi N, Mehaffy C. Whole-genome sequencing of the Mycobacterium tuberculosis Manila sublineage results in less clustering and better resolution than mycobacterial interspersed repetitive-unit-variable-number tandem-repeat (MIRU-VNTR) typing and spoligotyping. J Clin Microbiol. (2014) 52:37958. doi: 10.1128/JCM.01726-14

127. Kanduma E, McHugh TD, Gillespie SH. Molecular methods for Mycobacterium tuberculosis strain typing: a users guide. J Appl Microbiol. (2003) 94:781-91. doi: 10.1046/j.1365-2672.2003.01918.x

128. Mendez MV, Leon C, Escalona A, Abadia E, Da Mata O, de Waard $\mathrm{J}$, et al. [Evaluation of discriminatory power of molecular epidemiology techniques in Mycobacterium tuberculosis Venezuelan isolates]. Invest Clin. (2016) $57: 25-37$.

129. Murray M, Alland D. Methodological problems in the molecular epidemiology of tuberculosis. Am J Epidemiol. (2002) 155:56571. doi: 10.1093/aje/155.6.565

130. Abascal E, Perez-Lago L, Martinez-LirolaM, Chiner-Oms A, Herranz M, Chaoui I, et al. Whole genome sequencing-based analysis of tuberculosis (TB) in migrants: rapid tools for cross-border surveillance and to distinguish between recent transmission in the host country and new importations. Euro Surveill. (2019) 24:1800005. doi: 10.2807/1560-7917.ES.2019.24.4.1800005

131. Martinez-Lirola M, Jajou R, Mathys V, Martin A, Cabibbe AM, Valera A, et al. Integrative transnational analysis to dissect tuberculosis transmission events along the migratory route from Africa to Europe. J Travel Med. (2021) 28:taab054. doi: 10.1093/jtm/taab054

132. Tagliani E, Anthony R, Kohl TA, de Neeling A, Nikolayevskyy V, Kodmon C, et al. Use of a whole genome sequencing-based approach for Mycobacterium tuberculosis surveillance in Europe in 2017-2019: an ECDC pilot study. EuropRespir J. (2021) 57:2002272. doi: 10.1183/13993003.02272-2020

133. Walter KS, Tatara MB, Esther da Silva K, Moreira FMF, Dos Santos PCP, de Melo Ferrari DD, et al. Local and travel-associated transmission of tuberculosis at central western border of Brazil, 2014-2017. Emerging Infect Dis. (2021) 27:905-14. doi: 10.3201/eid2703.203839

134. Gehre F, Kumar S, Kendall L, Ejo M, Secka O, Ofori-Anyinam B, et al. A mycobacterial perspective on tuberculosis in west africa: significant geographical variation of $M$. africanum and other m tuberculosis complex lineages. PLoS Negl Trop Dis. (2016) 10:e0004408. doi: 10.1371/journal.pntd.0004408

135. Mekonnen D, Derbie A, Abeje A, Shumet A, Kassahun Y, Nibret E, et al. Genomic diversity and transmission dynamics of $M$. tuberculosis in Africa: a systematic review and meta-analysis. Int J Tuberc Lung Dis. (2019) 23:131426. doi: $10.5588 /$ ijtld. 19.0127

136. Almeida D, Rodrigues C, Ashavaid TF, Lalvani A, Udwadia ZF, Mehta A. High incidence of the Beijing genotype among multidrug-resistant isolates of Mycobacterium tuberculosis in a tertiary care center in Mumbai, India. Clin Infect Dis. (2005) 40:881-6. doi: 10.1086/427940
137. Arora J, Bhalla M, Sidiq Z, Lal P, Behera D, Rastogi N, et al. Predominance of Beijing genotype in extensively drug resistant Mycobacterium tuberculosis isolates from a tertiary care hospital in New Delhi, India. Int J Mycobacteriol. (2013) 2:109-13. doi: 10.1016/j.ijmyco.2013.03.001

138. Buu TN, van Soolingen D, Huyen MN, Lan NT, Quy HT, Tiemersma EW, et al. Increased transmission of Mycobacterium tuberculosis Beijing genotype strains associated with resistance to streptomycin: a population-based study. PLoS ONE. (2012) 7:e42323. doi: 10.1371/journal.pone.0042323

139. de Steenwinkel JE, ten Kate MT, de Knegt GJ, Kremer K, Aarnoutse RE, Boeree MJ, et al. Drug susceptibility of Mycobacterium tuberculosis Beijing genotype and association with MDR TB. Emerging Infect Dis. (2012) 18:660663. doi: 10.3201/eid1804.110912

140. Liang C, Zhang XX, Xing Q, Yi JL, Zhang YQ, Li CY, et al. [Study on the prevalence of Beijing genotype Mycobacterium tuberculosis and its relationship with second-line anti-tuberculosis drug resistance]. Zhonghua Jie $\mathrm{He} H \mathrm{He} H u$ Xi Za Zhi. (2020) 43:356-61. doi: 10.3760/cma.j.cn112147-20191215-00827

141. Nieto Ramirez LM, Ferro BE, Diaz G, Anthony RM, de Beer J, van Soolingen D. Genetic profiling of Mycobacterium tuberculosis revealed "modern" Beijing strains linked to MDR-TB from Southwestern Colombia. PLoS ONE. (2020) 15:e0224908. doi: 10.1371/journal.pone.0224908

142. Affolabi D, Anyo G, Faihun F, Sanoussi N, Shamputa IC, Rigouts L, et al. First molecular epidemiological study of tuberculosis in Benin. Int J Tuberc Lung Dis. (2009) 13:317-22.

143. Affolabi D, Faihun F, Sanoussi N, Anyo G, Shamputa IC, Rigouts L, et al. Possible outbreak of streptomycin-resistant Mycobacterium tuberculosis Beijing in Benin. Emerging Infect Dis. (2009) 15:112325. doi: 10.3201/eid1507.080697

144. Otchere ID, Asante-Poku A, Osei-Wusu S, Baddoo A, Sarpong E, Ganiyu $\mathrm{AH}$, et al. Detection and characterization of drug-resistant conferring genes in Mycobacterium tuberculosis complex strains: a prospective study in two distant regions of Ghana. Tuberculosis. (2016) 99:14754. doi: 10.1016/j.tube.2016.05.014

145. Sanchini A, Jandrasits C, Tembrockhaus J, Kohl TA, Utpatel C, Maurer $\mathrm{FP}$, et al. Improving tuberculosis surveillance by detecting international transmission using publicly available whole genome sequencing data. Euro Surveill. (2021) 26:1900677. doi: 10.2807/1560-7917.ES.2021.26.2.1900677

146. Wang F, Shao L, Fan X, Shen Y, Diao N, Jin J, et al. Evolution and transmission patterns of extensively drug-resistant tuberculosis in China. Antimicrob Agents Chemother. (2015) 59:818-25. doi: 10.1128/AAC.03504-14

147. Senghore M, Otu J, Witney A, Gehre F, Doughty EL, Kay GL, et al. Whole-genome sequencing illuminates the evolution and spread of multidrug-resistant tuberculosis in Southwest Nigeria. PLoS ONE. (2017) 12:e0184510. doi: 10.1371/journal.pone.0184510

148. Walker TM, Merker M, Knoblauch AM, Helbling P, Schoch OD, van der Werf MJ, et al. A cluster of multidrug-resistant Mycobacterium tuberculosis among patients arriving in Europe from the Horn of Africa: a molecular epidemiological study. Lancet Infect Dis. (2018) 18:431-40. doi: 10.1016/S1473-3099(18)30004-5

149. Cadmus S, Akinseye VO, van Soolingen D. Mycobacterium bovis in humans and $M$. tuberculosis in animals in Nigeria: an overview from 1975-2014. Int J Tuberc Lung Dis. (2019) 23:1162-70. doi: 10.5588/ijtld.18.0641

150. Otchere ID, van Tonder AJ, Asante-Poku A, Sanchez-Buso L, Coscolla M, Osei-Wusu S, et al. Molecular epidemiology and whole genome sequencing analysis of clinical Mycobacterium bovis from Ghana. PLoS ONE. (2019) 14:e0209395. doi: 10.1371/journal.pone.0209395

151. Baya B, Diarra B, Diabate S, Kone B, Goita D, Sarro YDS, et al. Association of Mycobacterium africanum infection with slower disease progression compared with Mycobacterium tuberculosis in malian patients with tuberculosis. Am J Trop Med Hyg. (2020) 102:36-41. doi: 10.4269/ajtmh.19-0264

152. de Jong BC, Adetifa I, Walther B, Hill PC, Antonio M, Ota M, et al. Differences between tuberculosis cases infected with Mycobacterium africanum, West African type 2, relative to Euro-American Mycobacterium tuberculosis: an update. FEMS Immunol Med Microbiol. (2010) 58:1025. doi: 10.1111/j.1574-695X.2009.00628.x 
153. Tientcheu LD, Bell A, Secka O, Ayorinde A, Otu J, Garton NJ, et al. Association of slow recovery of Mycobacterium africanum-infected patients posttreatment with high content of Persister-Like bacilli in pretreatment sputum. Int J Mycobacteriol. (2016) 5(Suppl. 1):S99100. doi: 10.1016/j.ijmyco.2016.09.033

154. Varghese B, Supply P, Shoukri M, Allix-Beguec C, Memish Z, Abuljadayel $\mathrm{N}$, et al. Tuberculosis transmission among immigrants and autochthonous populations of the eastern province of Saudi Arabia. PLoS ONE. (2013) 8:e77635. doi: 10.1371/journal.pone.0077635

155. Zetola NM, Moonan PK, Click E, Oeltmann JE, Basotli J, Wen XJ, et al. Population-based geospatial and molecular epidemiologic study of tuberculosis transmission dynamics, Botswana, 2012-2016. Emerging Infect Dis. (2021) 27:835-44. doi: 10.3201/eid2703.203840

156. Walker TM, Ip CL, Harrell RH, Evans JT, Kapatai G, Dedicoat MJ, et al. Whole-genome sequencing to delineate Mycobacterium tuberculosis outbreaks: a retrospective observational study. Lancet Infect Dis. (2013) 13:137-46. doi: 10.1016/S1473-3099(12)70277-3

157. Gardy JL, Johnston JC, Ho Sui SJ, Cook VJ, Shah L, Brodkin E, et al. Whole-genome sequencing and social-network analysis of a tuberculosis outbreak. N Engl J Med. (2011) 364:730-9. doi: 10.1056/NEJMoa100 3176

158. Lalor MK, Casali N, Walker TM, Anderson LF, Davidson JA, Ratna $\mathrm{N}$, et al. The use of whole-genome sequencing in cluster investigation of a multidrug-resistant tuberculosis outbreak. Europ Respir J. (2018) 51:1702313. doi: 10.1183/13993003.02313-2017

159. Walker TM, Lalor MK, Broda A, Saldana Ortega L, Morgan M, Parker L, et al. Assessment of Mycobacterium tuberculosis transmission in Oxfordshire, UK, 2007-12, with whole pathogen genome sequences: an observational study. Lancet Respir Med. (2014) 2:285-92. doi: 10.1016/S2213-2600(14) 70027-X

160. Walker TM, Merker M, Kohl TA, Crook DW, Niemann S, Peto TE. Whole genome sequencing for M/XDR tuberculosis surveillance and for resistance testing. Clin Microbiol Infect. (2017) 23:161-6. doi: 10.1016/j.cmi.2016.10.014

161. Walker TM, Monk P, Smith EG, Peto TEA. Contact investigations for outbreaks of Mycobacterium tuberculosis advances through whole genome sequencing. Clin Microbiol Infect. (2013) 19:796-802. doi: 10.1111/1469-0691.12183

162. Nebenzahl-Guimaraes H, Verhagen LM, Borgdorff MW, van Soolingen D. Transmission and progression to disease of Mycobacterium tuberculosis phylogenetic lineages in the Netherlands. J Clin Microbiol. (2015) 53:326471. doi: 10.1128/JCM.01370-15

163. de Jong BC, Hill PC, Brookes RH, Gagneux S, Jeffries DJ, Otu JK, et al. Mycobacterium africanum elicits an attenuated $\mathrm{T}$ cell response to early secreted antigenic target, $6 \mathrm{kDa}$, in patients with tuberculosis and their household contacts. J Infect Dis. (2006) 193:1279-86. doi: 10.1086/50 2977

164. Dosso M, Bonard D, Msellati P, Bamba A, Doulhourou C, Vincent V, et al. Primary resistance to antituberculosis drugs: a national survey conducted in Cote d'Ivoire in 1995-1996. Ivoirian Study Group on Tuberculosis Resistance. Int J Tuberc Lung Dis. (1999) 3:805-9.

165. Huet M, Rist N, Boube G, Potier D. [Bacteriological study of tuberculosis in Cameroon]. Revue de Tuberculose et de Pneumol. (1971 35:413-26.

166. Kallenius G, Koivula T, Ghebremichael S, Hoffner SE, Norberg R, Svensson E, et al. Evolution and clonal traits of Mycobacterium tuberculosis complex in Guinea-Bissau. J Clin Microbiol. (1999) 37:3872-8. doi: 10.1128/JCM.37.12.3872-3878.1999

167. Koro Koro F, Kamdem Simo Y, Piam FF, Noeske J, Gutierrez C, Kuaban C, et al. Population dynamics of tuberculous Bacilli in Cameroon as assessed by spoligotyping. J Clin Microbiol. (2013) 51:299-302. doi: 10.1128/JCM.01196-12

168. Niobe-Eyangoh SN, Kuaban C, Sorlin P, Cunin P, Thonnon J, Sola C, et al. Genetic biodiversity of Mycobacterium tuberculosis complex strains from patients with pulmonary tuberculosis in Cameroon. J Clin Microbiol. (2003) 41:2547-53. doi: 10.1128/JCM.41.6.2547-2553.2003

169. Bryant JM, Harris SR, Parkhill J, Dawson R, Diacon AH, van Helden $\mathrm{P}$, et al. Whole-genome sequencing to establish relapse or re-infection with Mycobacterium tuberculosis: a retrospective observational study.
Lancet Respir Med. (2013) 1:786-92. doi: 10.1016/S2213-2600(13) 70231-5

170. Guerra-Assuncao JA, Houben RM, Crampin AC, Mzembe T, Mallard K, Coll F, et al. Recurrence due to relapse or reinfection with Mycobacterium tuberculosis: a whole-genome sequencing approach in a large, populationbased cohort with a high HIV infection prevalence and active follow-up. $J$ Infect Dis. (2015) 211:1154-63. doi: 10.1093/infdis/jiu574

171. McIvor A, Koornhof H, Kana BD. Relapse, re-infection and mixed infections in tuberculosis disease. Pathog Dis. (2017) 75. doi: 10.1093/femspd/ $\mathrm{ftx} 020$

172. Unis G, Ribeiro AW, Esteves LS, Spies FS, Picon PD, Dalla Costa ER, et al. Tuberculosis recurrence in a high incidence setting for HIV and tuberculosis in Brazil. BMC Infect Dis. (2014) 14:548. doi: 10.1186/s12879-0140548-6

173. Velayutham B, Chadha VK, Singla N, Narang P, Gangadhar Rao V, Nair S, et al. Recurrence of tuberculosis among newly diagnosed sputum positive pulmonary tuberculosis patients treated under the Revised National Tuberculosis Control Programme, India: a multi-centric prospective study. PLoS ONE. (2018) 13:e0200150. doi: 10.1371/journal.pone.0200150

174. Zong Z, Huo F, Shi J, Jing W, Ma Y, Liang Q, et al. Relapse versus reinfection of recurrent tuberculosis patients in a national tuberculosis specialized hospital in Beijing, China. Front Microbiol. (2018) 9:1858. doi: 10.3389/fmicb.2018.01858

175. Sobkowiak B, Glynn JR, Houben R, Mallard K, Phelan JE, GuerraAssuncao JA, et al. Identifying mixed Mycobacterium tuberculosis infections from whole genome sequence data. BMC Genom. (2018) 19:613. doi: 10.1186/s12864-018-4988-z

176. WHO. Global Antimicrobial Resistance Surveillance System (GLASS). (2020). Available online at: https://www.who.int/glass/en/ (accessed May 4, 2021).

177. Fonseca JD, Knight GM, McHugh TD. The complex evolution of antibiotic resistance in Mycobacterium tuberculosis. Int J Infect Dis. (2015) 32:94100. doi: 10.1016/j.ijid.2015.01.014

178. Chisompola NK, Streicher EM, Muchemwa CMK, Warren RM, Sampson SL. Molecular epidemiology of drug resistant Mycobacterium tuberculosis in Africa: a systematic review. BMC Infect Dis. (2020) 20:344. doi: 10.1186/s12879-020-05031-5

179. Drobniewski F, Balabanova Y, Nikolayevsky V, Ruddy M, Kuznetzov S, Zakharova S, et al. Drug-resistant tuberculosis, clinical virulence, and the dominance of the Beijing strain family in Russia. JAMA. (2005) 293:272631. doi: 10.1001/jama.293.22.2726

180. WHO. Global Tuberculosis Report. (2014). Available online at: http://www. who.int/tb/publications/global_report/en/ (accessed June 6, 2015).

181. Perdigão J, Silva C, Maltez F, Machado D, Miranda A, Couto I, et al. Emergence of multidrug-resistant Mycobacterium tuberculosis of the Beijing lineage in Portugal and Guinea-Bissau: a snapshot of moving clones by whole-genome sequencing. Emerg Microbes Infect. (2020) 9:134253. doi: $10.1080 / 22221751.2020 .1774425$

182. Hanekom M, van der Spuy GD, Streicher E, Ndabambi SL, McEvoy CRE, Kidd $M$, et al. A recently evolved sublineage of the Mycobacterium tuberculosis Beijing strain family is associated with an increased ability to spread and cause disease. J Clin Microbiol. (2007) 45:1483-90. doi: 10.1128/JCM.02191-06

183. San LL, Aye KS, Oo NAT, Shwe MM, Fukushima Y, Gordon SV, et al. Insight into multidrug-resistant Beijing genotype Mycobacterium tuberculosis isolates in Myanmar. Int J Infect Dis. (2018) 76:10919. doi: 10.1016/j.ijid.2018.06.009

184. WHO. Global Tuberculosis Report. Geneva: World Health Organization (2012)

185. Collins $\mathrm{CH}$, Yates MD, Grange JM. Subdivision of Mycobacterium tuberculosis into five variants for epidemiological purposes: methods and nomenclature. J Hygiene. (1982) 89:23542. doi: 10.1017/S0022172400070765

186. Niemann S, Kubica T, Bange FC, Adjei O, Browne EN, Chinbuah MA et al. The species Mycobacterium africanum in the light of new molecular markers. J Clin Microbiol. (2004) 42:3958. doi: 10.1128/JCM.42.9.3958-3962. 2004

187. Ngoi JM, Quashie PK, Morang'a CM, Bonney JH, Amuzu DS, Kumordjie $\mathrm{S}$, et al. Genomic analysis of SARS-CoV-2 reveals local viral evolution 
in Ghana. Exp Biol Med. (2021) 246:960-70. doi: 10.1177/15353702209 75351

188. NIHR Global Health Research Unit on Genomic Surveillance of AMR. Whole-genome sequencing as part of national and international surveillance programmes for antimicrobial resistance: a roadmap. BMJ Glob Health. (2020) 5:e002244. doi: 10.1136/bmjgh-2019-00 2244

189. Prestinaci F, Pezzotti P, Pantosti A. Antimicrobial resistance: a global multifaceted phenomenon. Pathog Glob Health. (2015) 109:309-18. doi: 10.1179/2047773215Y.0000000030

190. Tobin DM. Host-directed therapies for tuberculosis. Cold Spring Harb Perspect Med. (2015) 5:a021196. doi: 10.1101/cshperspect. a021196

191. Zumla A, Rao M, Wallis RS, Kaufmann SH, Rustomjee R, Mwaba P, et al. Host-directed therapies for infectious diseases: current status, recent progress, and future prospects. Lancet Infect Dis. (2016) 16:e47-63. doi: 10.1016/S1473-3099(16) 00078-5
Conflict of Interest: The authors declare that the research was conducted in the absence of any commercial or financial relationships that could be construed as a potential conflict of interest.

Publisher's Note: All claims expressed in this article are solely those of the authors and do not necessarily represent those of their affiliated organizations, or those of the publisher, the editors and the reviewers. Any product that may be evaluated in this article, or claim that may be made by its manufacturer, is not guaranteed or endorsed by the publisher.

Copyright (c) 2021 Asare, Asante-Poku, Osei-Wusu, Otchere and Yeboah-Manu. This is an open-access article distributed under the terms of the Creative Commons Attribution License (CC BY). The use, distribution or reproduction in other forums is permitted, provided the original author(s) and the copyright owner(s) are credited and that the original publication in this journal is cited, in accordance with accepted academic practice. No use, distribution or reproduction is permitted which does not comply with these terms. 